\title{
PUNTA LAGUNA: UN SITIO PREHISPĀNICO DE QUINTANA ROO
}

\author{
antonio Benavides Castillo \\ Renée Lorelei Zapata Peraza \\ Centro Regional Campeche, INAH
}

\section{A Leonardo Falcón Kinil}

\section{Introducción}

A principios de 1984 el Instituto de Investigaciones Antropológicas de la UNAM y el Centro Regional del Sureste del INAH efectuaron la segunda temporada de un proyecto conjunto de excavación de unidades habitacionales en Cobá, Quintana Roo. Ese año la temporada de lluvias fue especialmente abundante, de manera que el nivel del lago Cobá subió $1.50 \mathrm{~m}$ (fenómeno similar al ocurrido en 1969 según informantes locales) e inundó sectores entre los que se encontraban los de las casetas de custodios y de venta de boletos para entrar a la zona arqueológica. En vista de tal situación y aprovechando los recursos económicos restantes del proyecto (por parte del INAH) durante noviembre y diciembre se construyeron nuevas instalaciones de acceso al sitio. Otras partidas fueron destinadas al mantenimiento anual del campamento del INAH y a la zona arqueológica (chapeos, reapertura de brechas y techumbres de materiales perecederos para estelas y tableros). Finalmente, una pequeña parte del presupuesto se aplicó a la prospección de los alrededores de Cobá, centrándonos en el sitio de Punta Laguna.

A pesar del poco tiempo (aproximadamente dos semanas) que se laboró en este último asentamiento debido a las constantes lluvias, y de los escasos recursos materiales y humanos empleados, ofrecemos una breve monografía que incluye: ubicación geográfica, generalidades sobre el ambiente y la comu. 
nidad, la historia del sitio, principales características de la arquitectura, el levantamiento topográfico de la mayoría de los edificios, algunas observaciones sobre cerámica de superficie, sobre escultura y estelas. También incluimos una visión del contexto regional de Punta Laguna y, por último, un apéndice referente a la visita efectuada a San Antonio Muyil.

Durante el trabajo de campo efectuado en Punta Laguna la población se mostró bastante accesible, no obstante su relativo aislamiento. Consideramos, desde la perspectiva de los ejidatarios, que no es del todo grata la llegada de extraños que alteran su vida cotidiana con preguntas, incursiones por sus propiedades, dirigiendo una serie de actividades no siempre comprensibles y, por ende, el sentirse como objetos de estudio. Por estas razones, así como por las molestias ocasionadas, agradecemos su colaboración a los habitantes de Punta Laguna.

Las ilustraciones fueron entintadas por la suscrita y Óscar Pinto Rivero.

\section{Ubicación y ambiente}

La zona arqueológica de Punta Laguna se localiza en el noroeste del estado de Quintana Roo (fig 1). Sus coordenadas geográficas, según las lecturas tomadas por el Geoceiver en 1983 , son $20^{\circ} 38^{\prime} 44.823^{\prime \prime}$ de latitud norte y $87^{\circ} 37^{\prime} 56.868^{\prime \prime}$ de longitud oeste; con una altura de 13.74 metros sobre el nivel del mar. En el Sistema de la Cuadrícula Universal Transversa de Mercator queda comprendida en el sector $16 \mathrm{Q}$ DT342828.

La entrada al sitio se ubica en el kilómetro 61 de la carretera Tulum-Nuevo Xcan (fig 2). La cinta asfáltica cruza el asentamiento de norte a sur por un espacio aproximado de tres kilómetros ( $\mathrm{km} 60$ al 62$)$.

El toponímico Punta Laguna se usa para designar, al mismo tiempo, al ejido, a la laguna más importante de éste y a la ranchería asentada en su orilla sur. La parte occidental del ejido aparentemente se encuentra en territorio yucateco, perteneciendo así al Municipio de Valladolid, Yucatán. A pesar de esto, más de las tres cuartas partes de la dotación ejidal se localizan en Quintana Roo. 
El ejido se divide en varias rancherías: Santa Rita, Yodzonot Laguna, Yoactún, Santa Elena, Lacah, Laguna Cruz, Esmeralda, Banco Cenote, Xanhá, Platanal, Buena Vista y Punta Laguna, entre otras. En total, la superficie que ocupa mide $16 \mathrm{~km}$ de ancho por $16 \mathrm{~km}$ de largo aproximadamente. Colinda con los ejidos de Chemax al poniente; Xcan al norte; mensura de Tres Reyes al oriente y mensura de Cobá al sur.

El ejido cuenta con seis lagunas, tales son:

1. Laguna Madera. Está ubicada a $10 \mathrm{~km}$ al norte de Punta Laguna (PL); tiene $700 \mathrm{~m}$ de largo en sentido este-oeste por $170 \mathrm{~m}$ de ancho en su eje norte-sur. Su forma vista en perspectiva aérea semeja un ave que mira al norte y es más profunda en el sector sur.

2. Laguna Chabela. Se encuentra a $3 \mathrm{~km}$ al noreste de PL; de norte a sur mide $500 \mathrm{~m}$, por $400 \mathrm{~m}$ de oriente a poniente. Presenta dos sectores de profundidad, el mayor al norte, en forma de un 8 horizontal, y al sur el más pequeño. La orilla occidental fue perturbada para la extracción de material al construirse la carretera.

3. Laguna Cruz. Se halla a $4 \mathrm{~km}$ al sur de PL. Es de forma irregular, con tres pequeños desniveles, dos en el extremo occidental y uno en el opuesto. Sus dimensiones son: un kilómetro de longitud máxima por $500 \mathrm{~m}$ de anchura máxima.

4. Dos Lagunas. Distan $4.5 \mathrm{~km}$ al oriente de PL. Son dos lagunas amorfas. La primera está ubicada al poniente y presenta tres depresiones en sentido norte-sur. Mide $750 \mathrm{~m}$ de largo por $250 \mathrm{~m}$ de ancho máximo. La segunda laguna, al poniente, contiene tres desniveles pequeños y dos grandes, también dispuestos en sentido norte-sur. Su longitud máxima es de $800 \mathrm{~m}$ por $300 \mathrm{~m}$ de ancho.

5. Campamento Hidalgo. Está a $7 \mathrm{~km}$ al sureste de PL, a un lado de la carretera.

6. Punta Laguna. Sus características serán descritas al referirnos al sitio.

Los pobladores de las rancherías proceden de Chemax y de Valladolid; casi siempre se trata de familias que han migrado espontáneamente en busca de terrenos deshabitados, debido a la presión demográfica y escasez de tierras existentes en el oriente de Yucatán. El total aproximado de ejidatarios de Punta 


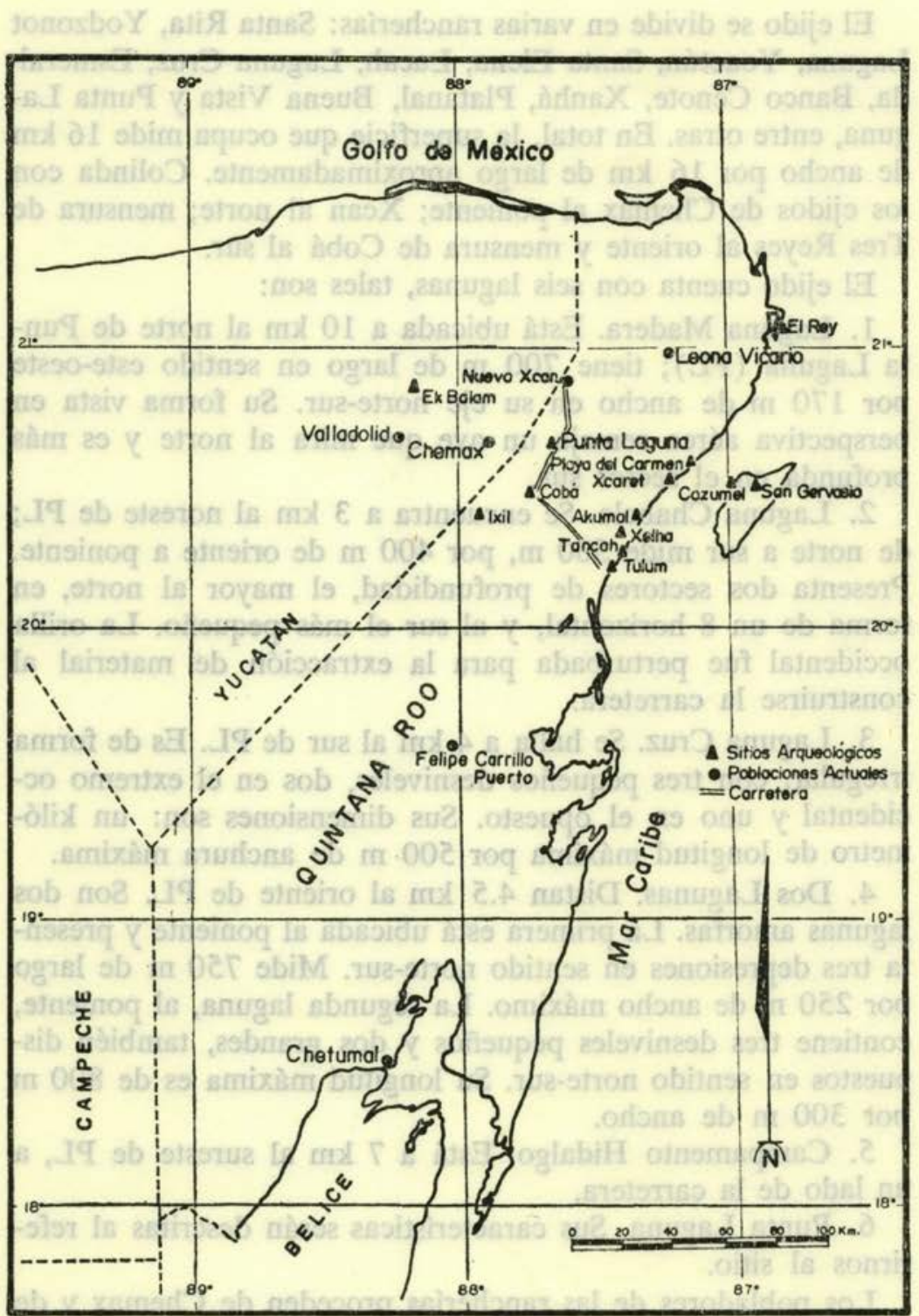

Figura 1 


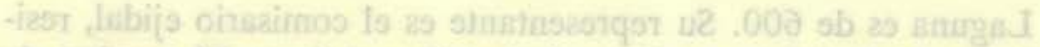

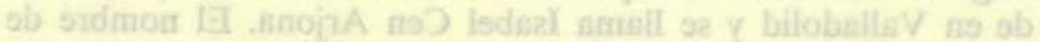

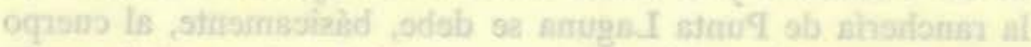

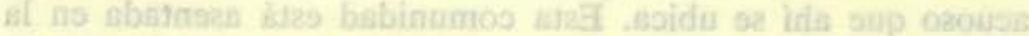

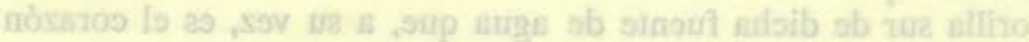

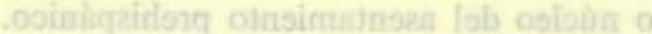

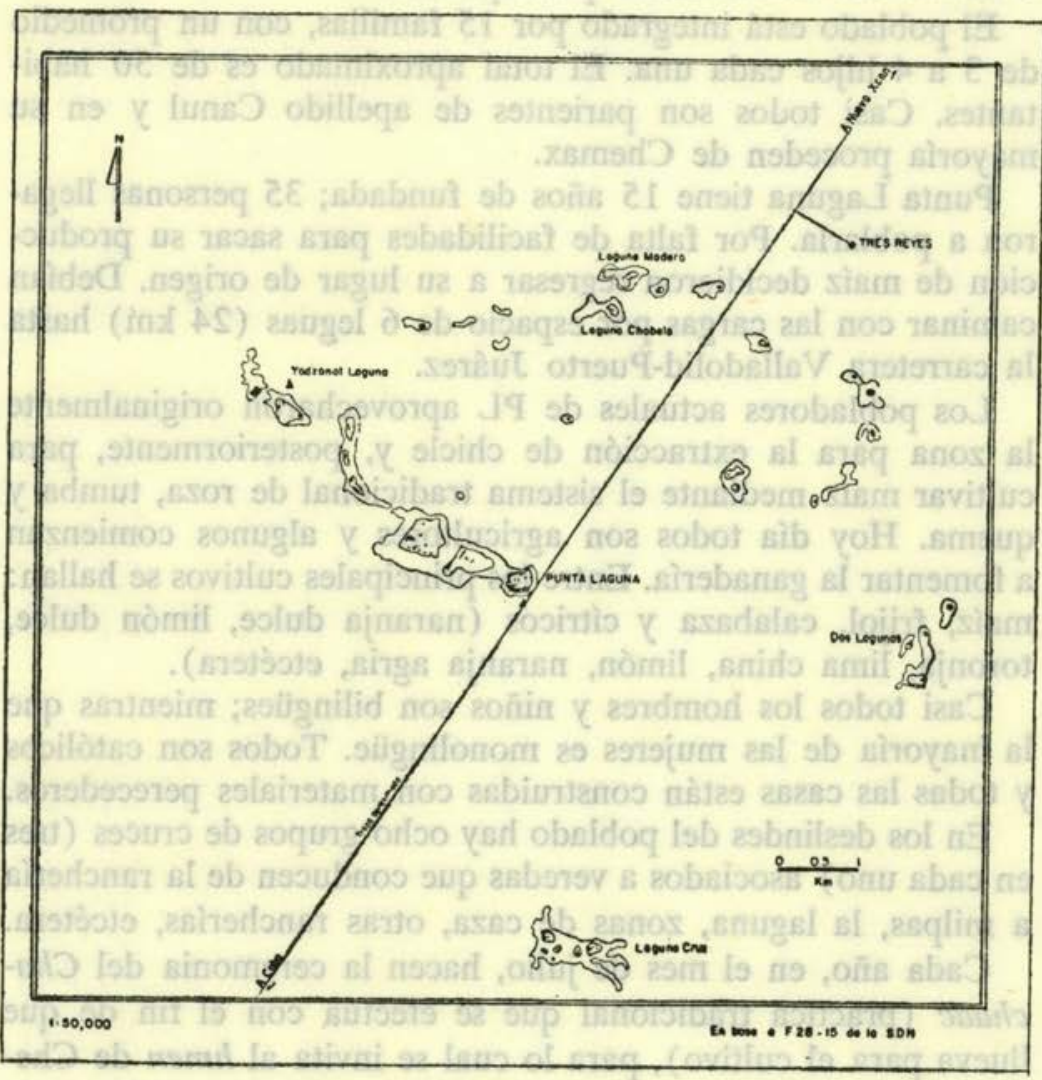

Figura 2

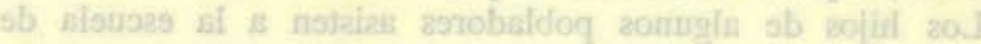

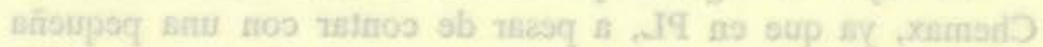

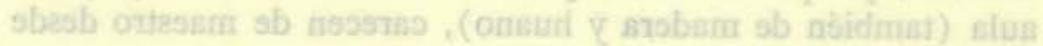

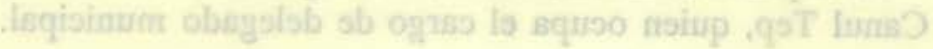


Laguna es de 600. Su representante es el comisario ejidal, reside en Valladolid y se llama Isabel Cen Arjona. El nombre de la ranchería de Punta Laguna se debe, básicamente, al cuerpo acuoso que ahí se ubica. Esta comunidad está asentada en la orilla sur de dicha fuente de agua que, a su vez, es el corazón o núcleo del asentamiento prehispánico.

El poblado está integrado por 15 familias, con un promedio de 3 a 4 hijos cada una. El total aproximado es de 50 habitantes. Casi todos son parientes de apellido Canul y en su mayoría proceden de Chemax.

Punta Laguna tiene 15 años de fundada; 35 personas llegaron a poblarla. Por falta de facilidades para sacar su producción de maíz decidieron regresar a su lugar de origen. Debían caminar con las cargas por espacio de 6 leguas $(24 \mathrm{~km})$ hasta la carretera Valladolid-Puerto Juárez.

Los pobladores actuales de PL aprovecharon originalmente la zona para la extracción de chicle y, posteriormente, para cultivar maíz mediante el sistema tradicional de roza, tumba y quema. Hoy día todos son agricultores y algunos comienzan a fomentar la ganadería. Entre los principales cultivos se hallan: maíz, frijol, calabaza y cítricos (naranja dulce, limón dulce, toronja, lima china, limón, naranja agria, etcétera).

Casi todos los hombres y niños son bilingües; mientras que la mayoría de las mujeres es monolingüe. Todos son católicos y todas las casas están construidas con materiales perecederos. En los deslindes del poblado hay ocho grupos de cruces (tres en cada uno) asociados a veredas que conducen de la ranchería a milpas, la laguna, zonas de caza, otras rancherías, etcétera. Cada año, en el mes de julio, hacen la ceremonia del Chachaac (práctica tradicional que se efectúa con el fin de que llueva para el cultivo), para lo cual se invita al hmen de Chemax. Para curaciones y otros servicios acuden con el hmen de Chac-né, a pocos kilómetros al poniente de Cobá.

Los hijos de algunos pobladores asisten a la escuela de Chemax, ya que en PL, a pesar de contar con una pequeña aula (también de madera y huano), carecen de maestro desde 1982.

El representante civil de los campesinos se llama Serapio Canul Tep, quien ocupa el cargo de delegado municipal. 
El área ocupada por la ranchería y sus alrededores es rica en recursos forestales, especialmente en cedro. La presencia de maderas comercializables ha ocasionado fricciones con explotadores foráneos. Aunado a lo anterior, la existencia de monumentos arqueológicos ha obligado a los ejidatarios a adquirir cierta conciencia de su patrimonio cultural y forestal. Sin embargo, existe una gran desunión interna y, por ende, frecuentes conflictos con el personal de las dependencias que han llegado a promover diversas actividades, así como con los habitantes de la región.

Por otra parte, a pesar de que nuestra área de estudio se ubica en una planicie, existen muchos afloramientos rocosos y marcados desniveles hasta de 3 y $4 \mathrm{~m}$. Esta topografía irregular, aunada a la abundante presencia de lagunas y bajos inundables en época de lluvias (akalché), es propia del norte de Quintana Roo.

Esta disparidad también se observa en la vegetación, en donde tenemos manchones de selva alta asociados a los montículos prehispánicos, con predominio del ramón; grandes extensiones de quemadal y zonas desmontadas para milpa en varias fases de regeneración.

Con respecto a los suelos, abunda el ek luum (estrato humocarbonatado muy oscuro y fértil; tierra negra); en cantidades regulares encontramos el kancab (suelo humocarbonatado de color rojo; menos fértil); y en menor frecuencia tenemos chac luum (sedimento rojizo, pegajoso, asociado a las áreas con agua en superficie) específicamente en las cercanías de la laguna.

La temperatura ambiental es cálida, con una isoterma anual media de $26^{\circ} \mathrm{C}$ y el clima es subhúmedo en cuanto a grado de humedad (AW2), con una precipitación pluvial anual media de 1400 a $1500 \mathrm{~mm}^{3}$ (CETENAL, 1970). El periodo de lluvias en la región ocurre de mayo a octubre. Sin embargo, también se registran ciclones, nortes, huracanes, etcétera, en época de secas, debido a la distribución errática de los fenómenos meteorológicos.

Durante el trabajo de campo se observaron varias especies florísticas que anotamos a continuación. La identificación se logró con base en el estudio de Barrera Marín, et al., 1976 y el de Mendieta, et al., 1981. 


\section{FLORA REGISTRADA EN PUNTA LAGUNA, QUINTANA ROO}

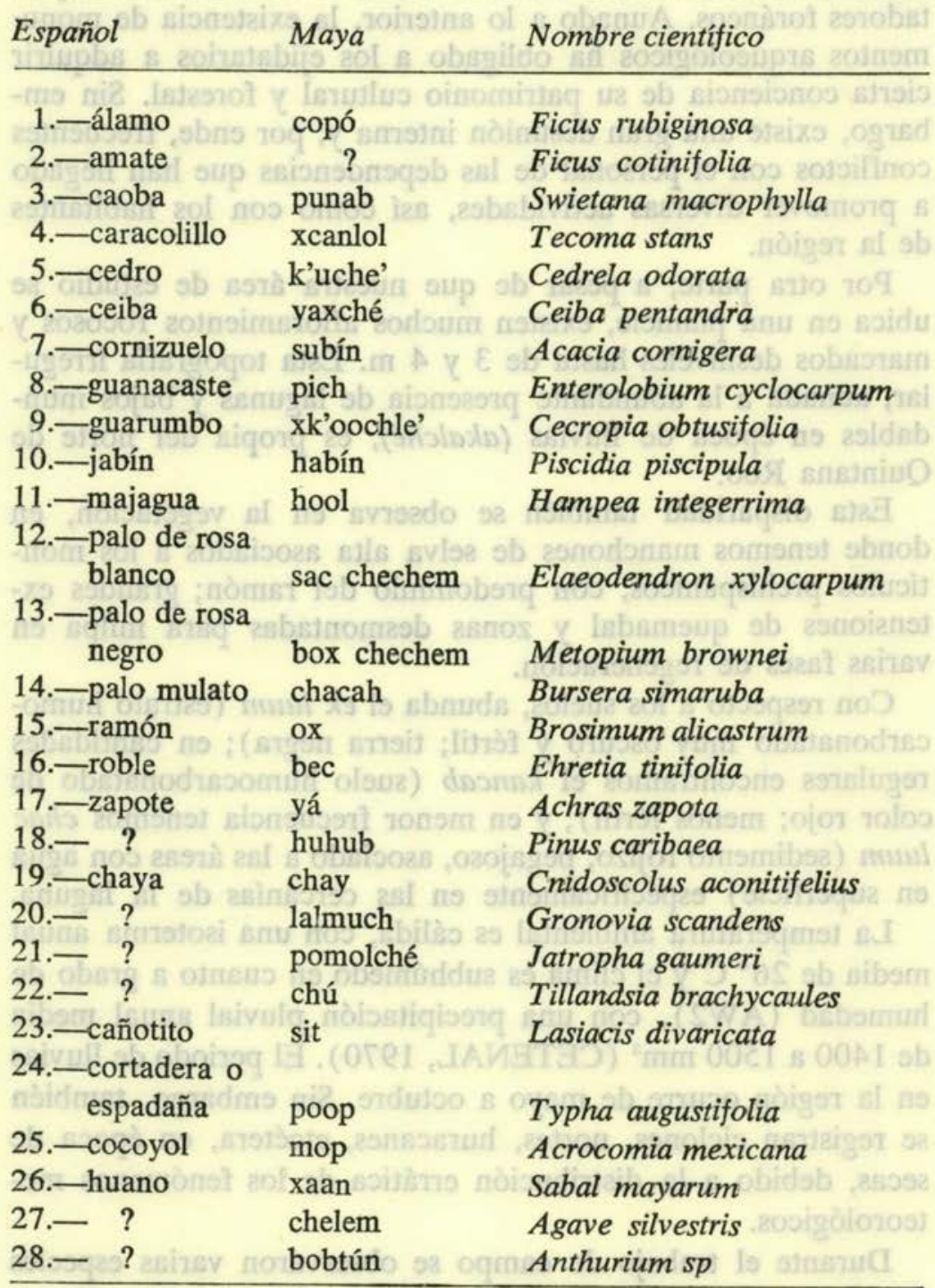


FAUNA REGISTRADA EN PUNTA LAGUNA, QUINTANA ROO

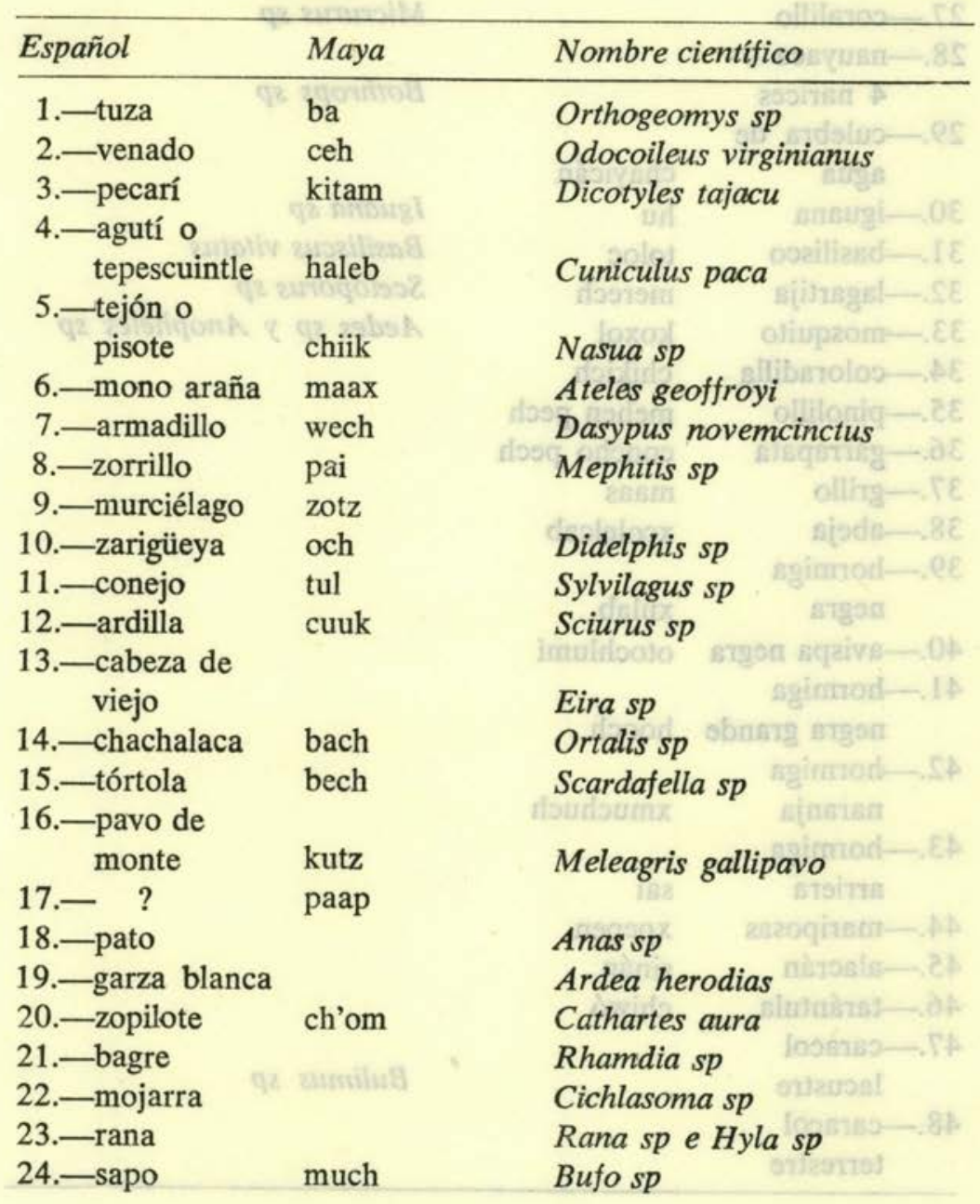




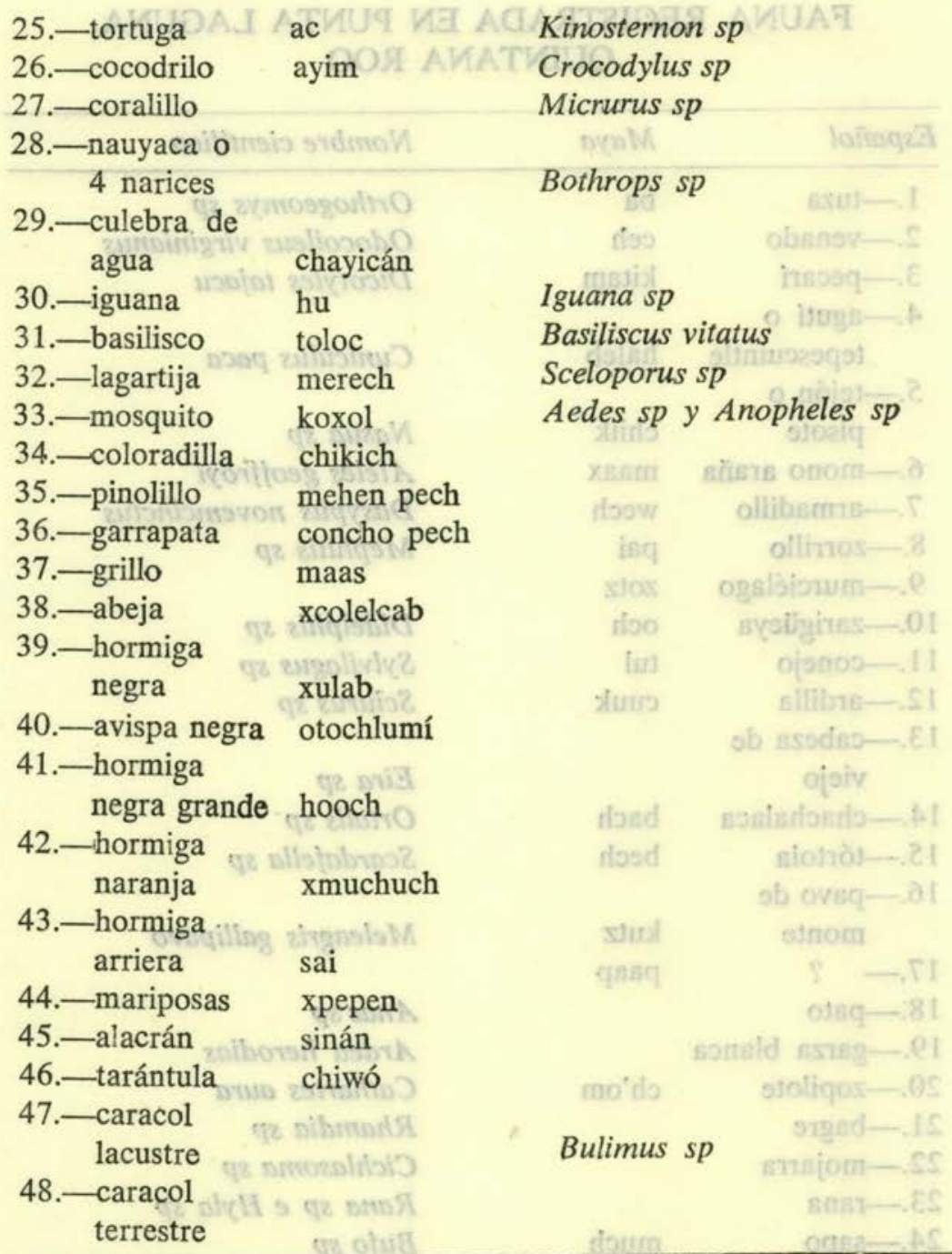




\section{TRABAJOS EN EL SITIO Y CARACTERISTICAS GEOGRÁFICAS}

El sitio arqueológico de Punta Laguna ha sido poco estudiado. Prácticamente las menciones al asentamiento se han efectuado en planos donde sólo se proporciona su ubicación.

Se cuenta con la localización precisa a partir de 1972 (mapas de la Secretaría de la Defensa Nacional; escala: 1:100,000). La segunda aproximación de la zona fue hecha en un plano general del norte de Quintana Roo (Benavides y Andrews, 1979: 50), pero dista mucho de ser exacta por haber sido reportada en forma de comunicación oral.

En 1981 la Secretaría de Asentamientos Humanos y Obras Públicas abrió una brecha del poblado de Punta Laguna hasta Chemax a fin de construir una carretera. Sin embargo, el proyecto se abandonó y la vegetación ha cubierto de nuevo ese trazo.

Dos años después, personal del Centro Regional del Sureste del Instituto Nacional de Antropología e Historia, registró las coordenadas geográficas, la altura sobre el nivel del mar y el U.T.M., como parte del proyecto Atlas Arqueológico de la Península de Yucatán.

Este trabajo contiene el resultado de las labores realizadas a fines de 1984, temporada en la que se hizo el levantamiento topográfico de la mayoría de las estructuras, una pequeña recolección de materiales de superficie y breves recorridos por el área.

El elemento más llamativo del paisaje es la laguna, denominada Punta Laguna. Su eje longitudinal corre en sentido sureste-noroeste y sus dimensiones aproximadas, con base en fotografía aérea (F28 14 y 15 de la Secretaría de la Defensa Nacional, 1968), son: $1.900 \mathrm{~km}$ de longitud máxima (1.750 $\mathrm{km}$ mínima) por $750 \mathrm{~m}$ de ancho máximo. Desde el aire se advierten tres sectores de diferente profundidad en el mismo cuerpo acuoso. El primero se halla en el extremo sureste, es el más cercano a la población y el de menores dimensiones. En él se localiza una pequeña caleta, aproximadamente al centro de la orilla sur. El segundo sector es casi el doble de grande que el anterior y la tercera zona, además de ser la mayor, pre- 
senta dos extensiones de menor profundidad y se halla en el extremo noroeste.

Durante el trabajo de campo recorrimos algunas orillas y navegamos en una canoa hecha de ceiba a lo largo y ancho de la laguna. En esas labores observamos que, a diferencia de las lagunas de la región, como por ejemplo Cobá, el fondo de los dos primeros sectores de Punta Laguna es de arena. También verificamos una gran profundidad $(20 \mathrm{~m})$ en cada uno de los tres sectores que la integran. La unión de las tres partes es menos profunda $(2 \mathrm{~m})$ y presenta zonas de vegetación acuática en donde predomina el cañotito (sit, en lengua maya; Lasiacis divaricata). Alrededor de la laguna la flora está formada por espadaña (poop, en maya; Typha angustifolia) y lirio acuático (lolhá, en maya; Nymphaea ampla). Se asegura que en el tercer sector habita un cocodrilo (ayim, en maya; Crocodylus sp.).

Caleta. En la orilla sureste de la laguna, en fotografía aérea, se observa una formación triangular (isósceles) en cuyo vértice se ubica la caleta. La entrada de ésta tiene $26 \mathrm{~m}$ de ancho; el espacio interior mide $38 \mathrm{~m}$ de largo máximo por $32 \mathrm{~m}$ de ancho promedio (fig 3 ). Sus paredes semejan un pequeño acantilado con mucho derrumbe. En algunos puntos la altura promedio de las paredes llega a los $6 \mathrm{~m}$. En el sector sur del inte-

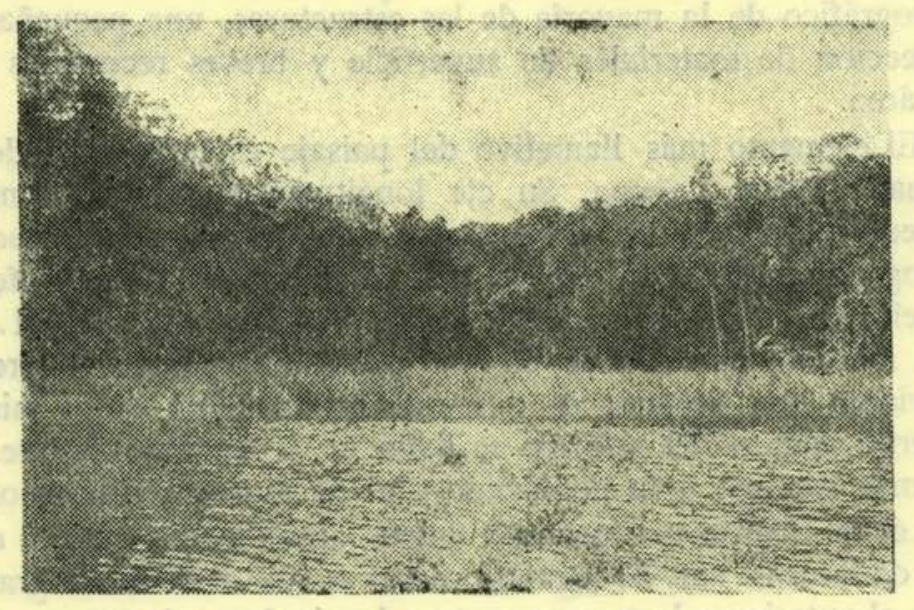

Figura 3 
rior de la caleta, en contacto con el agua, hay piedras alineadas que dan la impresión de haber formado un pequeño muelle.

Dentro de la caleta se ubican cuatro cuevas chicas. La primera está en la parte sur, es la más amplia, está inundada y no se observó material cultural. En el sector poniente de la caleta se hallan las otras tres cuevas, de menores dimensiones que la primera.

La segunda cueva es la más pequeña, su acceso es una grieta angosta y no se halló material en su superficie. La tercera cueva es el principal refugio de los monos. Ahí encontramos cerámica y huesos de animales. La cuarta cavidad es la más próxima a la entrada de la caleta, por el norte, y no se visitó por estar inundada y por tener otochlumi, avispa negra cuyo piquete, aseguraron, produce fiebre.

Cenote. Ésta es la principal fuente de abastecimiento de agua de la comunidad. Se localiza a $180 \mathrm{~m}$ al poniente de la carretera. La boca es una grieta que mide $1.90 \mathrm{~m}$ de largo por 40 $\mathrm{cm}$ de ancho y $4 \mathrm{~m}$ de espesor. A $14 \mathrm{~m}$ al oriente del cenote

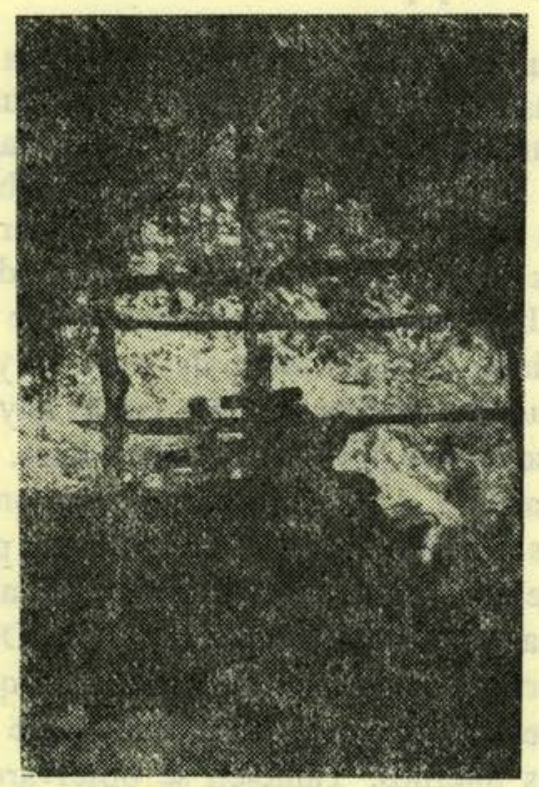

Figura 4 
hay un techado de materiales perecederos que cubre tres cruces (dos de madera y una de piedra, formación natural que también semeja un ave) (fig 4). Estas cruces, a su vez, "cuidan" al cenote y delimitan una de las entradas a la ranchería. En este lugar se efectúan anualmente las ceremonias del Chachaac.

Alrededor de la grieta de acceso al cenote se observaron fisuras que, tarde o temprano, ocasionarán el desprendimiento de la costra caliza, de modo que obtendrá el aspecto típico de muchos otros cenotes.

Antes de penetrar al cenote los informantes recomendaron fumar en el interior para prevenir un "mal viento". El hacerlo ocasionaría que éste se fuera, de manera similar a como las serpientes huyen ante el olor del tabaco.

El espejo del agua está a $11.50 \mathrm{~m}$ de profundidad (diciembre, 1984) (fig 5). Sin embargo, los informantes señalaron que en tiempo de secas el nivel del agua baja hasta $3 \mathrm{~m}$. El manto freático alcanza una altura de 3 a $4 \mathrm{~m}$. En el interior del cenote se observaron varias oquedades, pero no fueron exploradas por estar inundadas y para evitar la contaminación del líquido.

Cueva. Se encuentra a $300 \mathrm{~m}$ al poniente de la caleta. Presenta tres entradas dispuestas en sentido norte-sur, pero sólo es accesible por una de ellas. Una entrada está tapada con grandes piedras en la superficie, y la última está abierta y por ella penetra mucha luz pero es imposible descender.

$\mathrm{El}$ acceso es una grieta que mide $1.40 \mathrm{~m}$ de largo por 50 $\mathrm{cm}$ de ancho. Las paredes bajan abruptamente y por ello descendimos mediante una escalera de troncos y bejucos hasta una profundidad de $4.50 \mathrm{~m}$. En ese punto hay una gran acumulación de escombro, producto de derrumbes. A partir de ahí la cavidad se amplía y presenta una mayor profundidad.

La cueva es grande: tiene como medidas promedio $40 \mathrm{~m}$ de largo en sentido norte-sur por $30 \mathrm{~m}$ de ancho en su eje este-oeste y una altura aproximada de $30 \mathrm{~m}$. Observamos gran cantidad de derrumbes, lo cual ha ocasionado que existan marcados desniveles y oquedades irregulares que a simple vista parecen pasajes internos. También se observaron dos grandes estalactitas; una pila circular, natural, de $1.50 \mathrm{~m}$ de diámetro 

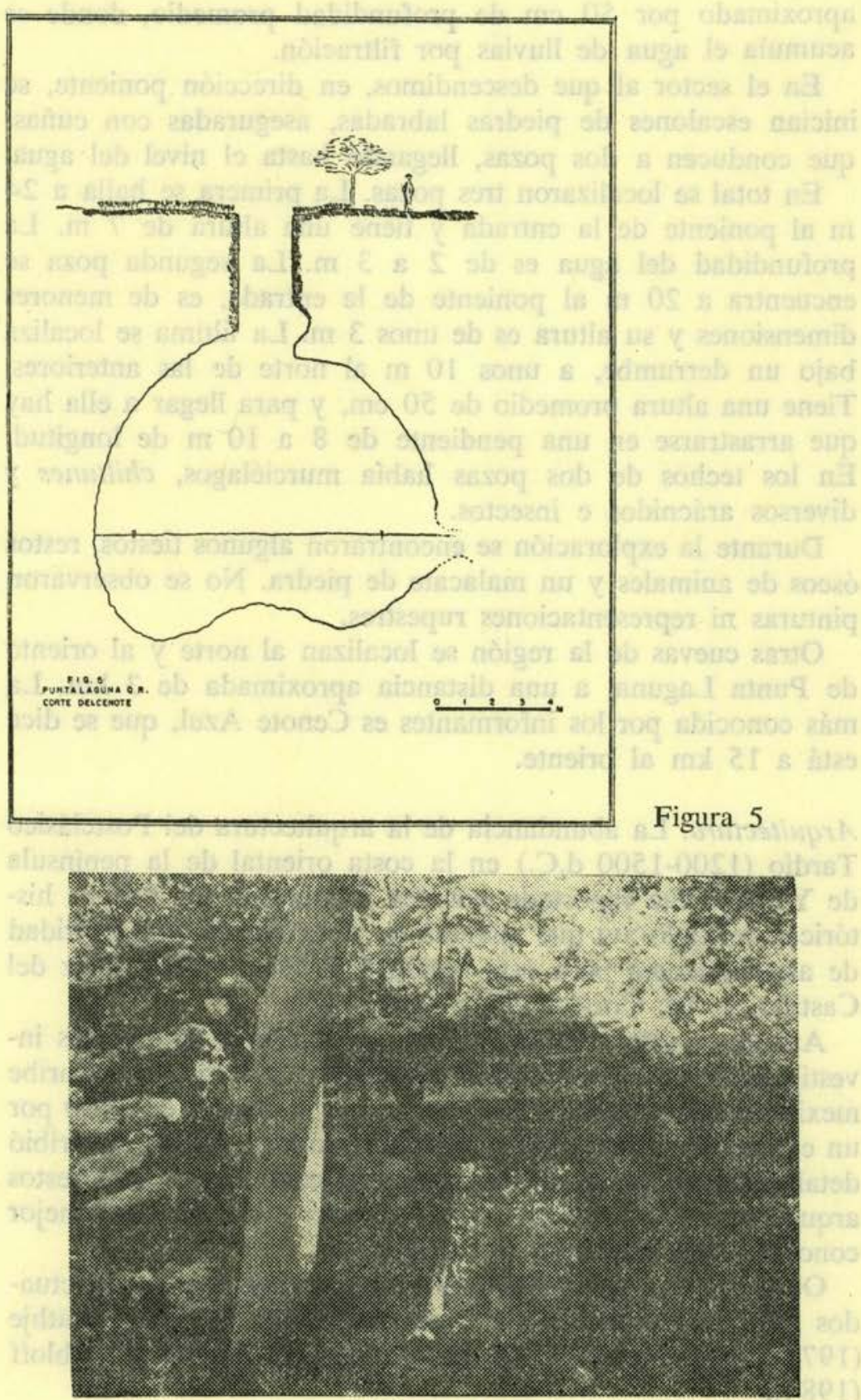

Figura 6

Estudios de Cultura Maya. Vol. XVIII, 1991 Instituto de Investigaciones Filológicas/ Centro de Estudios Mayas, UNAM ISSN 0185-2574 
aproximado por $50 \mathrm{~cm}$ de profundidad promedio, donde se acumula el agua de lluvias por filtración.

En el sector al que descendimos, en dirección poniente, se inician escalones de piedras labradas, aseguradas con cuñas, que conducen a dos pozas, llegando hasta el nivel del agua.

En total se localizaron tres pozas. La primera se halla a 24 $\mathrm{m}$ al poniente de la entrada y tiene una altura de $7 \mathrm{~m}$. La profundidad del agua es de 2 a $3 \mathrm{~m}$. La segunda poza se encuentra a $20 \mathrm{~m}$ al poniente de la entrada, es de menores dimensiones y su altura es de unos $3 \mathrm{~m}$. La última se localiza bajo un derrumbe, a unos $10 \mathrm{~m}$ al norte de las anteriores. Tiene una altura promedio de $50 \mathrm{~cm}$, y para llegar a ella hay que arrastrarse en una pendiente de 8 a $10 \mathrm{~m}$ de longitud. En los techos de dos pozas había murciélagos, chiltunes y diversos arácnidos e insectos.

Durante la exploración se encontraron algunos tiestos, restos óseos de animales y un malacate de piedra. No se observaron pinturas ni representaciones rupestres.

Otras cuevas de la región se localizan al norte y al oriente de Punta Laguna, a una distancia aproximada de $3 \mathrm{~km}$. La más conocida por los informantes es Cenote Azul, que se dice está a $15 \mathrm{~km}$ al oriente.

Arquitectura. La abundancia de la arquitectura del Postclásico Tardío (1200-1500 d.C.) en la costa oriental de la península de Yucatán fue reportada por vez primera en las fuentes históricas del siglo xvi que apuntan la presencia de gran cantidad de asentamientos para esta región (cfr. Díaz, 1958; Díaz del Castillo, 1970; Cortés, 1973; entre otros).

Aunado a esto, existen valiosas aportaciones de diversos investigadores de la arqueología peninsular. La costa del Caribe mexicano fue estudiada inicialmente en la década de 1920 por un equipo de la Institución Carnegie. Lothrop (1924) describió detalladamente las características arquitectónicas de esos restos arqueológicos, acuñando así el llamado estilo Tulum, mejor conocido hoy día como Costa Oriental.

Otros estudios fundamentales para esta área son los efectuados por Thompson (1945); Sanders (1960); Sabloff y Rathje (1975); Andrews IV y Andrews (1975); Freidel y Sabloff (1984). 
Sanders (1960: 226), con base en el estudio de los materiales cerámicos de 33 sitios, confirma la temporalidad de la arquitectura Costa Oriental para los últimos tres siglos de la época prehispánica o Postclásico Tardío.

Entre los asentamientos mayas más conocidos que comparten estas características tenemos a los de Cancún (El Rey) (Vargas, 1978); El Meco (Andrews y Robles, en prensa); Playa del Carmen (González y Trejo, 1981); San Gervasio (Sabloff y Rathje, op. cit.; Freidel y Sabloff, op. cit.); Tancah (Sanders, op. cit.; Miller, 1977); Tulum (Lothrop, op. cit.); Xcaret (Andrews, op. cit.); y Xelhá (Lothrop, op. cit.; Sanders, op. sit.; Robles, 1980).

Además de estos sitios costeros, en el interior se han reportado ciudades precolombinas con restos de construcciones típicas de la Costa Oriental. En el norte se han registrado dos pequeños templos sobre un edificio en Santa María, hoy Leona Vicario (Escalona, 1946: 546). En el noroeste sabemos de gran cantidad de construcciones similares en Cobá (Thompson et al., 1932; Benavides, 1981a, 1981b; Folan et al., 1983) y otra más en Ixil (Robles, 1976: 27-30). En la parte central e interior de Quintana Roo contamos con los sitios de Tanpak, Platanal y Las Milpas, cada uno con un edificio del estilo Costa Oriental (Escalona, op. cit.: 537-539, 591, 592). El ejemplo más occidental de este tipo de construcciones en la región fue reportado en Ekbalam por Charnay (1978: 36). A lo anterior vienen a sumarse los vestigios de Hidalgo, Yaxché, Yoactún y Punta Laguna.

Gran parte de la arquitectura que aún se conserva en pie en Punta Laguna presenta mucha similitud con la de los edificios considerados como del estilo Costa Oriental. Generalmente se trata de construcciones de mampostería que no son de carácter habitacional; son basamentos de poca altura con escalinatas (de 6 a 7 gradas) que conducen a un pequeño templo con el dintel siempre remetido, las paredes presentan una marcada inclinación dada ex professo y las cubren gruesos aplanados de estuco como para subsanar el mal trabajo del labrado (fig 6). Los materiales que se utilizaron para su elaboración fueron básicamente obtenidos de los recursos naturales de la región: piedra caliza de varias durezas, el sascab o piedra arenosa, la cal, el agua y diversas maderas duras. 
Las piedras usadas fueron de dos clases: de relleno y de recubrimiento (fig. 8). Las primeras, la mayoría de las veces, son pedacería unida con argamasa formando el núcleo del edificio y las segundas son piedras burdamente cortadas o sin labrar que conforman las paredes de las estructuras. Estas últimas, en ocasiones, están calzadas con cuñas para emparejar las hiladas.

El sascab se extraía de yacimientos que casi siempre se hallan bajo roca superficial intemperizada y antes del nivel freático. Este material era aprovechado para diversos fines, tales como: base y recubrimiento de aplanados para pisos y muros (estuco), argamasa, modelados decorativos, etcétera.

La cal se obtenía calcinando piedra caliza y se usaba primordialmente para elaborar la mezcla, agregando agua y sascab, que unía a las piezas.

Los mayas precolombinos utilizaron la madera para manufacturar diversas partes de sus edificios, como por ejemplo: morillos, dinteles, cimbras (?), etcétera. Además, ésta conformaba las paredes y vigas principales de las casas habitación. En Punta Laguna, a pesar de que no encontramos restos de este material, sí contamos con los orificios donde iban los morillos (cuatro agujeros dispuestos simétricamente para contener troncos, hasta de $10 \mathrm{~cm}$ de diámetro, en el interior de las paredes de algunos templos) y numerosos cimientos de construcciones de materiales perecederos.

Una minoría de los edificios mayas del sitio presentan elementos arquitectónicos que parecen ser del periodo Clásico Tardío (700-1000/1100 d.C.). Generalmente se trata de plataformas de posible carácter habitacional. Tienen una altura promedio de $2 \mathrm{~m}$, son de planta rectangular y las piedras que las componen presentan un mejor labrado que los edificios postclásicos. En la parte superior ocasionalmente se hallan alineaciones de piedras formando cuadrángulos que semejan los cimientos de varias divisiones de una misma construcción de materiales perecederos.

La mayoría de las veces estas obras son de dimensiones medianas, alcanzando una longitud de $21 \mathrm{~m}$ por $7 \mathrm{~m}$ de ancho como promedio. Tres ejemplos son las estructuras 2,6 y 7 .

El sistema constructivo es similar al de los otros edificios de la región. Se utilizan grandes piedras irregulares a manera de relleno y se levantan los muros aparentes que al mismo 


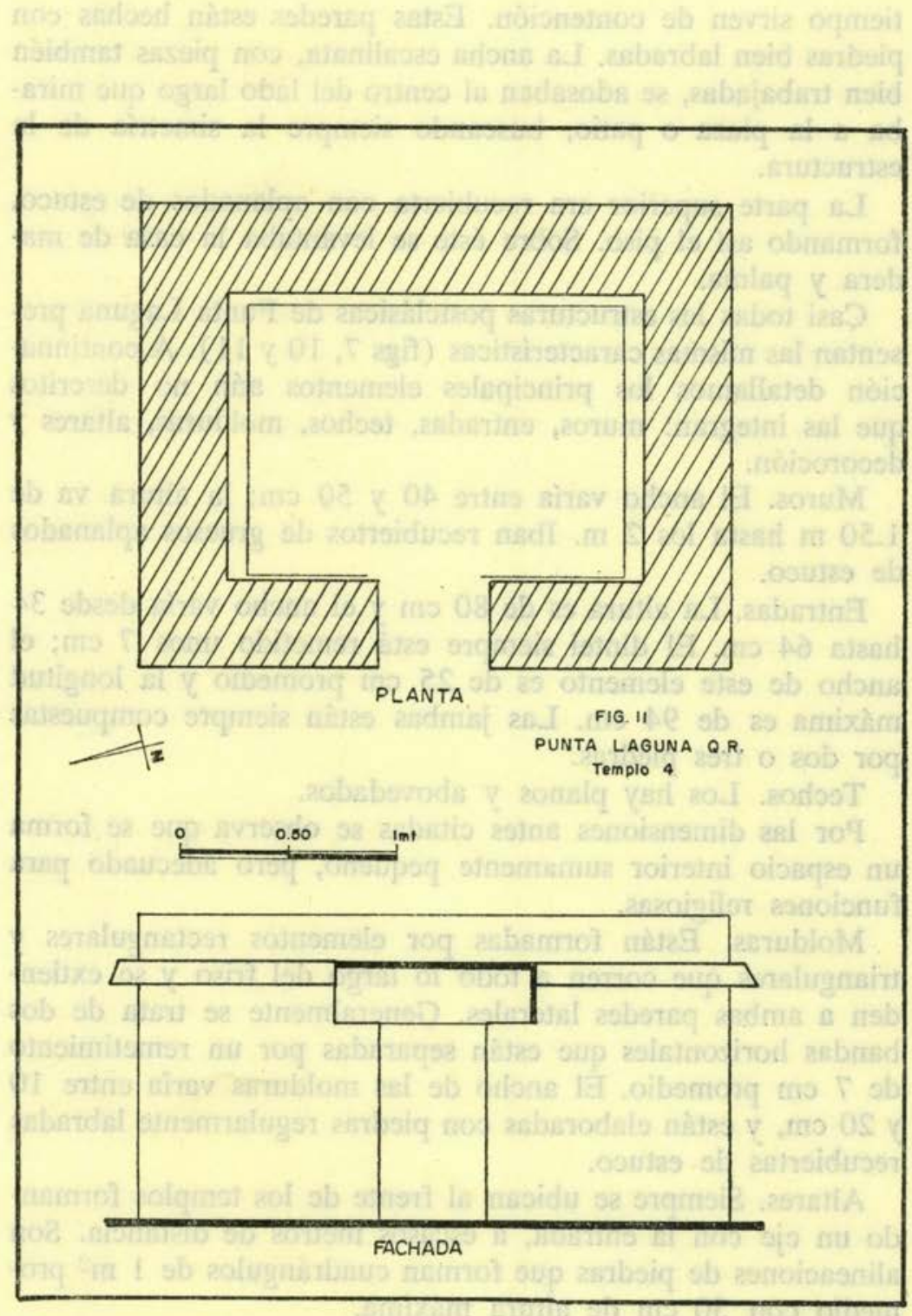

Figura 7

Estudios de Cultura Maya. Vol. XVIII, 1991 Instituto de Investigaciones Filológicas/

Centro de Estudios Mayas, UNAM

ISSN 0185-2574 
tiempo sirven de contención. Estas paredes están hechas con piedras bien labradas. $\mathrm{La}$ ancha escalinata, con piezas también bien trabajadas, se adosaban al centro del lado largo que miraba a la plaza o patio, buscando siempre la simetría de la estructura.

La parte superior era recubierta con aplanados de estuco, formando así el piso. Sobre éste se levantaba la casa de madera y palma.

Casi todas las estructuras postclásicas de Punta Laguna presentan las mismas características (figs 7,10 y 11). A continuación detallamos los principales elementos aún no descritos que las integran: muros, entradas, techos, molduras, altares y decoroción.

Muros. El ancho varía entre 40 y $50 \mathrm{~cm}$; la altura va de $1.50 \mathrm{~m}$ hasta los $2 \mathrm{~m}$. Iban recubiertos de gruesos aplanados de estuco.

Entradas. La altura es de $80 \mathrm{~cm}$ y el ancho varía desde 34 hasta $64 \mathrm{~cm}$. El dintel siempre está remetido unos $7 \mathrm{~cm}$; el ancho de este elemento es de $25 \mathrm{~cm}$ promedio y la longitud máxima es de $94 \mathrm{~cm}$. Las jambas están siempre compuestas por dos o tres piedras.

Techos. Los hay planos y abovedados.

Por las dimensiones antes citadas se observa que se forma un espacio interior sumamente pequeño, pero adecuado para funciones religiosas.

Molduras. Están formadas por elementos rectangulares y triangulares que corren a todo lo largo del friso y se extienden a ambas paredes laterales. Generalmente se trata de dos bandas horizontales que están separadas por un remetimiento de $7 \mathrm{~cm}$ promedio. El ancho de las molduras varía entre 10 y $20 \mathrm{~cm}$, y están elaboradas con piedras regularmente labradas recubiertas de estuco.

Altares. Siempre se ubican al frente de los templos formando un eje con la entrada, a escasos metros de distancia. Son alineaciones de piedras que forman cuadrángulos de $1 \mathrm{~m}^{2}$ promedio con $50 \mathrm{~cm}$ de altura máxima.

Decoración. Se detectaron restos de pintura azul sobre varios de los aplanados de estuco.

En términos generales, los restos de construcciones hallados en Punta Laguna pueden clasificarse en seis variantes de diver- 


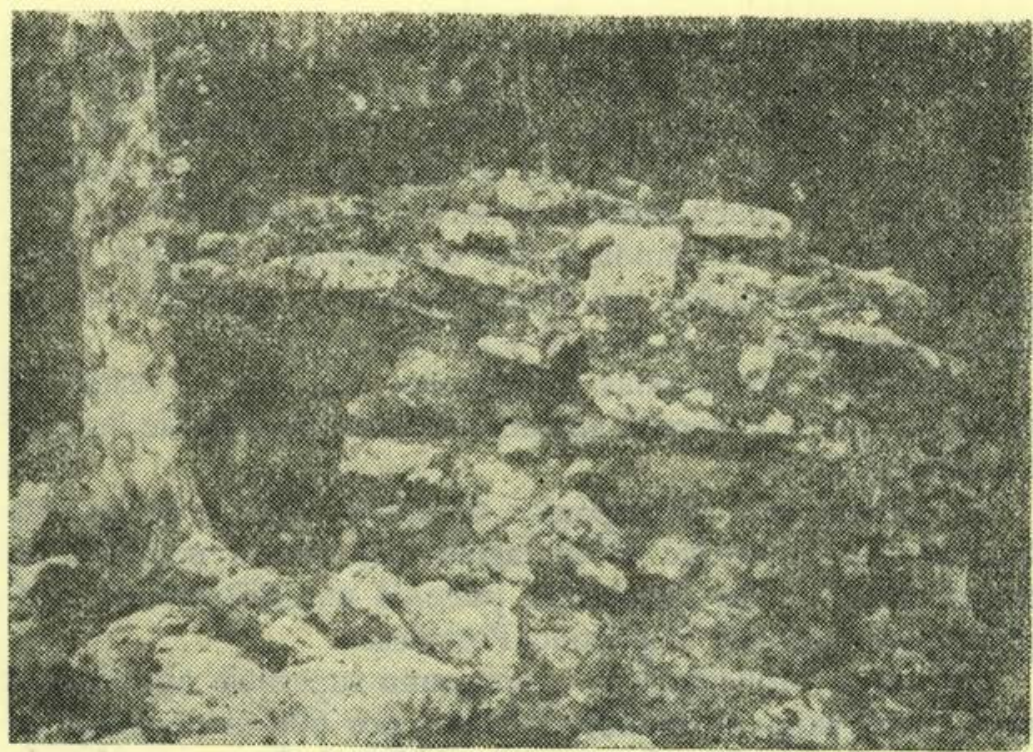

Figura 8

sas dimensiones, desde unas cuantas piedras que conforman un pequeño espacio construido, hasta grandes basamentos de varios niveles que concentran una alta inversión de fuerza de trabajo (fig 8).

1. Cimientos de casas habitación. Se trata de hiladas de piedra que encierran espacios rectangulares que servían como desplante de las construcciones de materiales perecederos. Encontramos estos elementos en la estructura 8 y en las que se hallan sobre las plataformas III y IV.

2. Altares. Son pequeñas construcciones, generalmente de planta cuadrangular, de 1 a $3 \mathrm{~m}$ por lado y $50 \mathrm{~cm}$ de altura promedio. En Punta Laguna se localizaron seis altares, generalmente asociados a fragmentos de cerámica tardía. Uno está frente a la E 1; dos al poniente de la E 6; otro al sur de la E 7; otro al noroeste de la E 9 y el último al sur de la E 18.

3. Plataformas sencillas con bloques grandes y burdos. Éstas son de la época postclásica y han sido descritas previamente. Se localizaron 21 construcciones con estas características. 
4. Plataformas grandes con escalinatas y bloques mejor labrados. Pertenecen al periodo Clásico y también han sido descritas con anterioridad. Se hallaron cuatro unidades de este tipo: las estructuras 2, 6, 7 y 9 (fig 10). Las tres últimas conforman una plaza cerrada al norte por la Plataforma I.

5. Basamentos piramidales con escalinatas y templos, algunos de éstos derruidos. En Punta Laguna se hallaron seis de tales basamentos: $1,3,17,29$ y 31 (fig 7 y 11 ).

6. Grandes plataformas poligonales, con varios desniveles sobre los que se erigieron algunos edificios. Se trata de las plataformas I al IV.

El asentamiento prehispánico de Punta Laguna se localiza básicamente al sureste de la laguna del mismo nombre. La mayor parte de las estructuras presenta una distribución irregular y corresponde al periodo Postclásico.

Los restos arqueológicos ocupan una superficie aproximada de $1 \mathrm{~km}$ de largo en sentido este-oeste por $600 \mathrm{~m}$ de ancho en un eje norte-sur. En el extremo occidental de ese rectángulo imaginario se halla una cueva (véase el apartado correspondiente). Aproximadamente al centro encontramos la caleta y en el sector oriental tenemos 40 unidades arquitectónicas: 36 estructuras diversas y cuatro grandes plataformas poligonales.

La parte aparentemente más antigua del sitio, del periodo Clásico, se ubica a unos $300 \mathrm{~m}$ al oriente de la caleta y el asentamiento creció a su alrededor, de modo que los edificios postclásicos se erigieron al norte y noreste de dicho centro.

En conjunto, la zona arqueológica puede dividirse en dos grupos: el arriba mencionado, con bastante espacio entre la mayoría de sus edificios y otro grupo localizado a unos $200 \mathrm{~m}$ al noreste del anterior. Ese segundo grupo es mucho más compacto pues está formado por una gran plataforma irregular asociada a siete estructuras.

En total pueden distinguirse dos plazas y dos patios. Las primeras se encuentran en el grupo principal; una, delimitada por las estructuras 6,7 y 9 con una superficie de $14500 \mathrm{~m}^{2}$ y cerrada al norte por la Plataforma I; y la otra rodeada por los edificios $3,13,14,15$ y 17 , con $6400 \mathrm{~m}^{2}$. Ambas se encuentran al mismo nivel.

En cuanto a los patios, tenemos uno sobre la Plataforma II con la Estructura 4 al norte y la 5 al poniente. $\mathrm{El}$ otro patio 
se halla sobre la Plataforma IV, encerrado por los edificios 30 , 31,35 y 36 .

Algunos edificios están orientados a los puntos cardinales, pero la mayoría no parece seguir ese patrón. Cabe anotar que casi no se observa arquitectura en pie. Por lo que respecta a la planta de las construcciones, hallamos 21 rectangulares, 13 cuadrangulares y 6 poligonales. De estas últimas la 13 y la 17 fueron incluidas como tales debido al derrumbe y remoción reciente de piedras que impidieron detectar las esquinas originales.

\section{Escultura}

La única pieza esculpida que hallamos en Punta Laguna fue un cráneo con espiga que estaba entre las piedras de derrumbe del lado sur de la Estructura 3. Tiene grabados, en bajo relieve, las órbitas, la fosa nasal (en forma de triángulo) y seis incisiones verticales que podemos dividir en: cuatro incisivos y dos caninos. Las dimensiones del cráneo son: $21 \mathrm{~cm}$ de ancho en la parte superior; $32 \mathrm{~cm}$ de largo y $15 \mathrm{~cm}$ de ancho en la mandíbula. La espiga mide $48 \mathrm{~cm}$ de largo, un grosor de $20 \mathrm{~cm}$ y su perímetro es de $78 \mathrm{~cm}$.

Posiblemente la pieza estaba empotrada en algún sector del edificio pero esto fue imposible averiguarlo debido a la fuerte remoción de piedras ocurrida un año antes en ese lado de la estructura.

Esculturas similares se han encontrado en otros sitios como Chichén Itzá (Óscar Liera, comunicación personal, 1985) y Cobá.

Estela 1. Se localiza a $8.40 \mathrm{~m}$ al poniente del segundo templo estilo Costa Oriental (Estructura 3). Sus dimensiones son: $1.27 \mathrm{~m}$ de largo por $53 \mathrm{~cm}$ de ancho y $19 \mathrm{~cm}$ de espesor. Aún conserva restos de aplanado de estuco en dos sectores irregulares. Su estado de conservación es malo, está muy erosionada y fragmentada. La parte superior es la mejor conservada. No se halló la espiga, ni representación alguna (fig 9).

Estela 2. Se encuentra al pie de la Estructura 5. Sus dimensiones son: $1.70 \mathrm{~m}$ de largo por $1.10 \mathrm{~m}$ de ancho y $20 \mathrm{~cm}$ de 


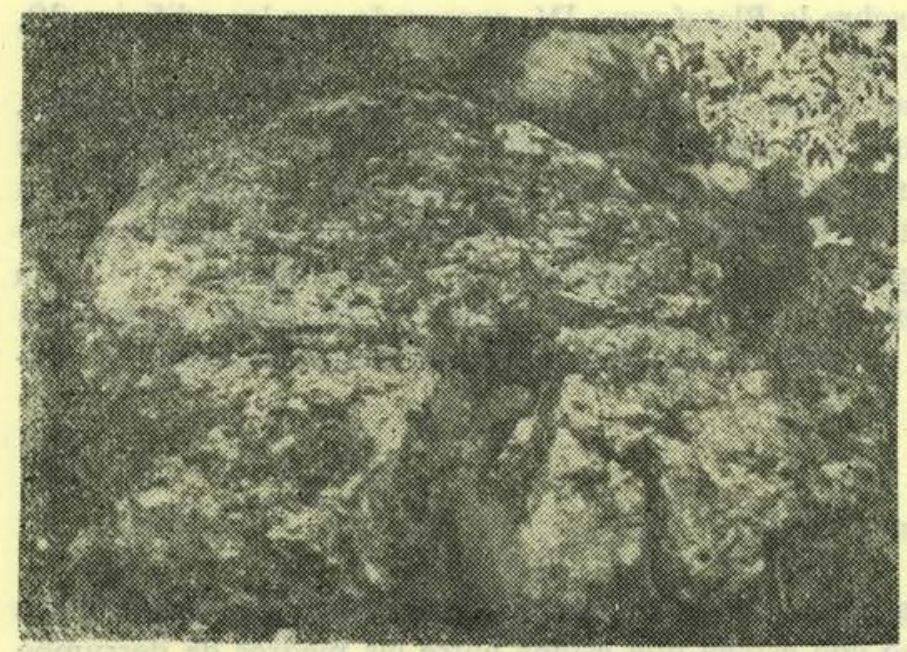

espesor. También está muy erosionada y fracturada en cuatro secciones. Tampoco se registró ningún relieve o grabado.

Estela 3. Este monumento se halla a $16 \mathrm{~m}$ al oriente de la Estructura 8. Sus dimensiones son: $1.25 \mathrm{~m}$ de largo por $58 \mathrm{~cm}$ de ancho y $18 \mathrm{~cm}$ de espesor. Se encuentra en mal estado de conservación. Este monolito fue movido de su lugar original por los habitantes de la localidad y actualmente se encuentra al pie de la escalinata del edificio.

\section{Cerámica}

Los tiestos recolectados durante los recorridos y prospecciones realizados en Punta Laguna fueron sumamente escasos y las más de las veces se hallaron muy erosionados. Sin embargo se detectó una mayor cantidad de material cerámico en la cueva.

$\mathrm{Si}$ bien la mayor parte de la arquitectura visible corresponde al periodo Postclásico Tardío, los tepalcates evidencian una secuencia cronológica que se inicia en el Preclásico Tardío y finaliza en el siglo xv, aunque no se observó una completa continuidad en cuanto a los complejos cerámicos. 


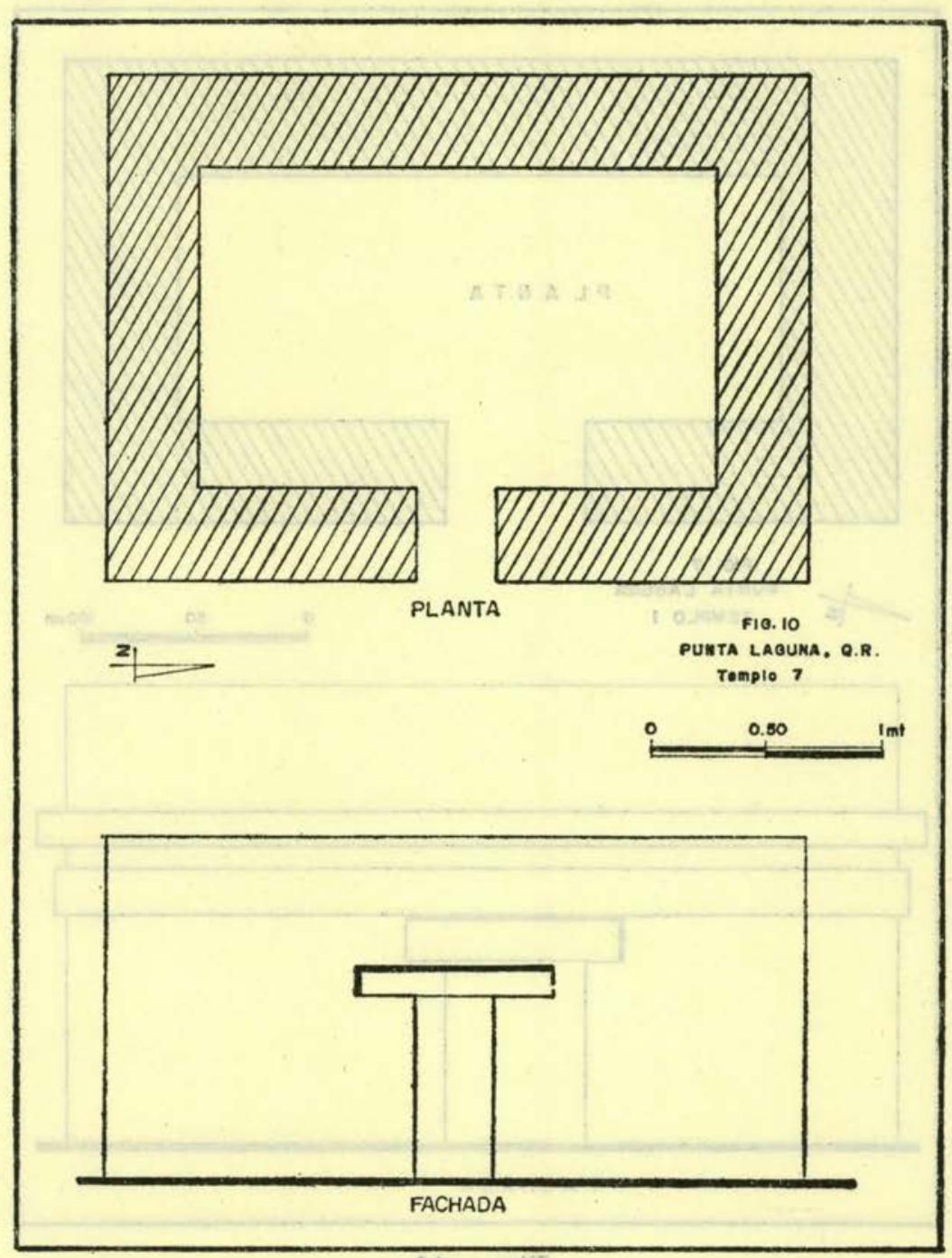

Figura 10 
ESTUdiOS DE CULTURA MAYA, XVIII

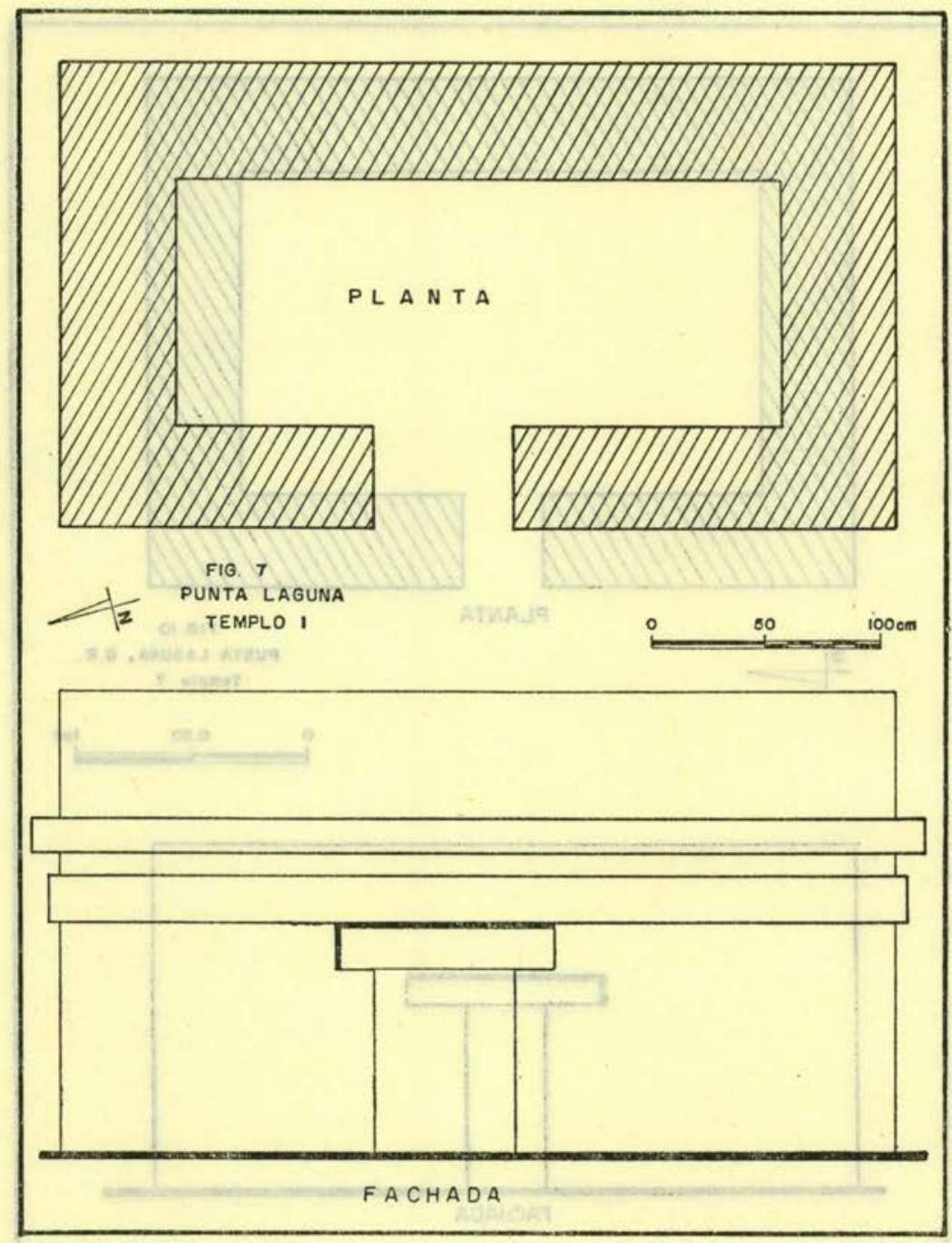

Figura 11

Estudios de Cultura Maya. Vol. XVIII, 1991

Instituto de Investigaciones Filológicas/

Centro de Estudios Mayas, UNAM

ISSN 0185-2574 
Los tipos identificados incluyen Sierra rojo, Huachinango inciso bicromo y posiblemente Laguna verde inciso, por lo que respecta al complejo más temprano (800 a.C.-100 d.C.) (Chicanel o bien Tihosuco). Después siguen cronológicamente materiales Cetelac desgrasante vegetal, correspondientes al complejo Cochuah (300-600 d.C.). Hay una relativa abundancia de tiestos Yokat estriado, del Complejo Cehpech (8001000 d.C.); algunos tepalcates Mama rojo, es decir del Complejo Hocabá (1200-1300 d.C.) y finalmente fragmentos de incensarios antropomorfos Chen mul modelado inciso, fechados entre 1300 y 1450 d.C. (Complejo Tases).

$\mathrm{El}$ análisis de los materiales cerámicos fue elaborado tomando como guía las útiles publicaciones de Smith (1971) y Ball (1978).

\section{Alrededores}

En las cercanías de Punta Laguna hay, cuando menos, nueve zonas arqueológicas, según la información oral recabada. Las distancias y los rumbos están proporcionados a partir del sitio en estudio: 1) Yaxché, a $5.7 \mathrm{~km}$ al sur; 2) Yodzonot Laguna, a $6 \mathrm{~km}$ al noroeste; 3) Hidalgo o Campamento Ruinas, a $8 \mathrm{~km}$ al sur, al borde de la carretera; 4) Santa Rosa, a $5 \mathrm{~km}$ al norte; 5) Cocoyol, a $32 \mathrm{~km}$ al norte; 6 Xlacah, a $17.7 \mathrm{~km}$ al suroeste; 7) Xtimul, a $21.7 \mathrm{~km}$ al oriente; 8) Yoactún, a $10 \mathrm{~km}$ al oeste; y 9) Xkacá, a $16 \mathrm{~km}$ al poniente.

De todos los lugares mencionados solamente visitamos Yodzonot Laguna. Existe una vereda de acceso que conduce a la ranchería sobre el sitio arqueológico. La brecha se halla al poniente del kilómetro 63.5 de la carretera Tulum-Nuevo Xcan, y corre por la orilla norte de Punta Laguna, rumbo al poniente.

Nosotros optamos por llegar a la zona atravesando la laguna en la canoa mencionada (fig 12) y caminando sólo cuatro kilómetros. Durante ese recorrido pasamos por la orilla poniente de la laguna Xcanhá. Más adelante vimos plataformas de piedras grandes, irregulares y constantes afloramientos rocosos.

Yodzonot Laguna está asentada en una amplia nivelación artificial en el terreno, actualmente ocupada, además de la plaza central de la ranchería, por las casas de los principales habi- 


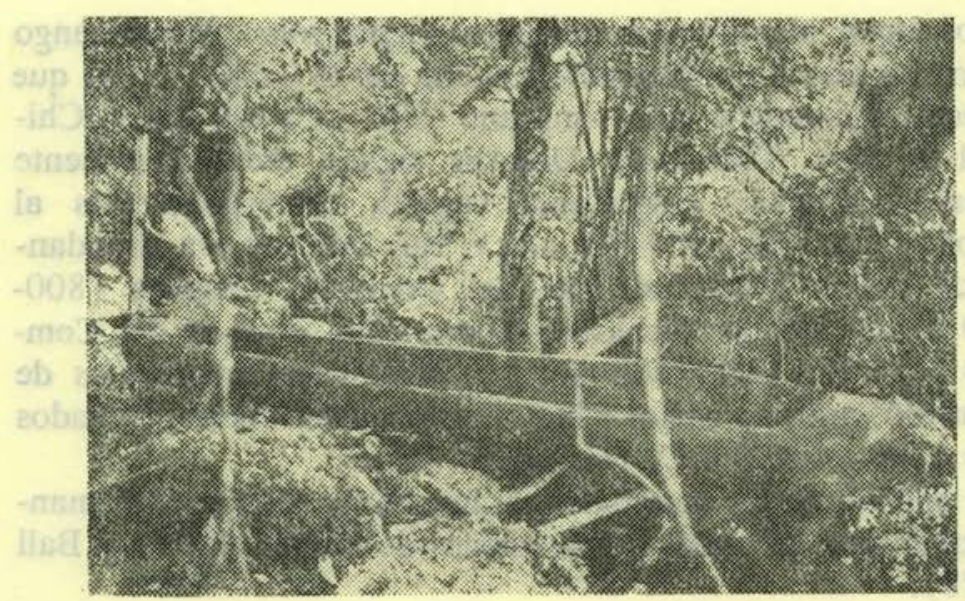

Figura 12

tantes del lugar, la escuela y la iglesia. Todas las construcciones son de materiales perecederos.

La primordial fuente de agua es un cenote que se halla a unos $200 \mathrm{~m}$ al oriente de la plaza principal. Tiene un diámetro aproximado de $4 \mathrm{~m}$, por $6 \mathrm{~m}$ de profundidad.

Todos los pobladores son católicos y efectúan rezos por carecer de servicios religiosos formales. También practican el Chachaac y cuentan con un cuadrado de mampostería donde habitualmente bailan jarana. En el interior de la iglesia, sobre una mesa que hace las veces de altar, hay imágenes de diversos santos sin que ninguno ocupe un lugar primordial. Sobre este altar, cada año, se coloca un mantel bordado con la imagen de la Virgen de Nuestra Señora de la Merced, ángeles, motivos florales y los apellidos de la familia donante que, casi siempre, es la del comisario ejidal en turno. La celebración religiosa se efectúa el 23 de septiembre.

A esta iglesia acuden periódicamente los habitantes de Tres Reyes, Yoactún, Xkacá y Punta Laguna.

En total, la comunidad está formada por 80 ejidatarios. La mayoría son niños y 14 de ellos, que están en edad escolar, asisten regularmente a la escuela. Ahí se les proporciona la educación básica y, en caso de desear continuar sus estudios, deben ir a Chemax o a Valladolid. El maestro permanece du- 
rante dos años presentando así su servicio social a la Secretaría de Educación Pública.

Las actividades económicas principales son la agricultura y, en menor escala, la ganadería. Antiguamente ésta era una zona chiclera.

Por lo que toca a salubridad, al tiempo de nuestra visita, en diciembre de 1984, existían varios casos de paludismo que atendía personal de la Secretaría de Salubridad y Asistencia. Esta enfermedad también se reportó en Yoactún.

Por otra parte, las casas restantes que integran Yodzonot Laguna fueron construidas sobre plataformas prehispánicas y montículos, donde se halla gran cantidad de metates.

La fauna del lugar es similar a la de Punta Laguna, pero además se dice que hay mono saraguato (Alouata sp.) y jaguar (Felis onca).

Al igual que Punta Laguna, esta ranchería está reconocida por Valladolid y su representante civil es Humberto Uitzil. 


\section{COMENTARIOS FINALES}

Punta Laguna no es un fenómeno aislado, sino que forma parte de uno mayor, como lo evidencian varios sitios similares de diversas localidades prehispánicas de Quintana Roo con arquitectura denominada Costa Oriental.

Sus orígenes parecen iniciarse en el periodo Preclásico Tardío para luego cobrar auge durante el Postclásico. Seguramente la presencia permanente de agua en superficie motivó su fundación y facilitó el asentamiento humano. En diez kilómetros a la redonda no parece existir otra fuente del vital líquido de las dimensiones de Punta Laguna.

El sitio más importante de la región fue Cobá, a $20 \mathrm{~km}$ al suroeste de Punta Laguna, y debieron existir relaciones entre ellos, no sólo por su contemporaneidad sino también por encontrarse a un día de camino. Es interesante notar que en Punta Laguna, en superficie, no se halló ningún fragmento de obsidiana o de sílex, materias primas que son comunes en Cobá como producto del comercio que sostuvo con el sur del área maya.

Otro punto de relación entre Punta Laguna y Cobá es la presencia de estelas y esculturas asociadas a la arquitectura monumental. Desafortunadamente los restos pétreos no conservan representaciones grabadas.

Aparentemente, durante el periodo Clásico en los alrededores de Cobá no se erigen muchos edificios pero, al ocurrir el llamado "colapso", además de una reorganización política se da un reacomodo de población que permite el crecimiento de asentamientos tardíos con la construcción de numerosas obras. Punta Laguna sería un ejemplo de lo anterior en el interior de Quintana Roo. Las ruinas de Yodzonot Laguna, en caso de ser postclásicas, apoyarían también esta interpretación.

Después, durante unos quinientos años (finales del siglo xv a 1970) el asentamiento prehispánico al borde de la laguna permaneció en el silencio, aislado y desconocido por el mundo occidental. Quizá fue visitado ocasionalmente por indígenas rebeldes durante el siglo XIX o más tarde por cazadores y chicleros.

Además de su patrimonio arqueológico, hoy día Punta Laguna posee importantes elementos ecológicos (selva y laguna) 
dignos de estudio y preservación. Si bien su riqueza forestal ha disminuido en cierta medida, aún conserva un buen número de especies florísticas y algunas faunísticas que bien vale la pena proteger. La presencia de estos elementos podría despertar, a mediano plazo, el interés por explotarlos turísticamente. Los mismos ejidatarios están interesados en ello. Sería entonces deseable que se tomaran las medidas necesarias para conocer y aprovechar racionalmente la riqueza ambiental de Punta Laguna.

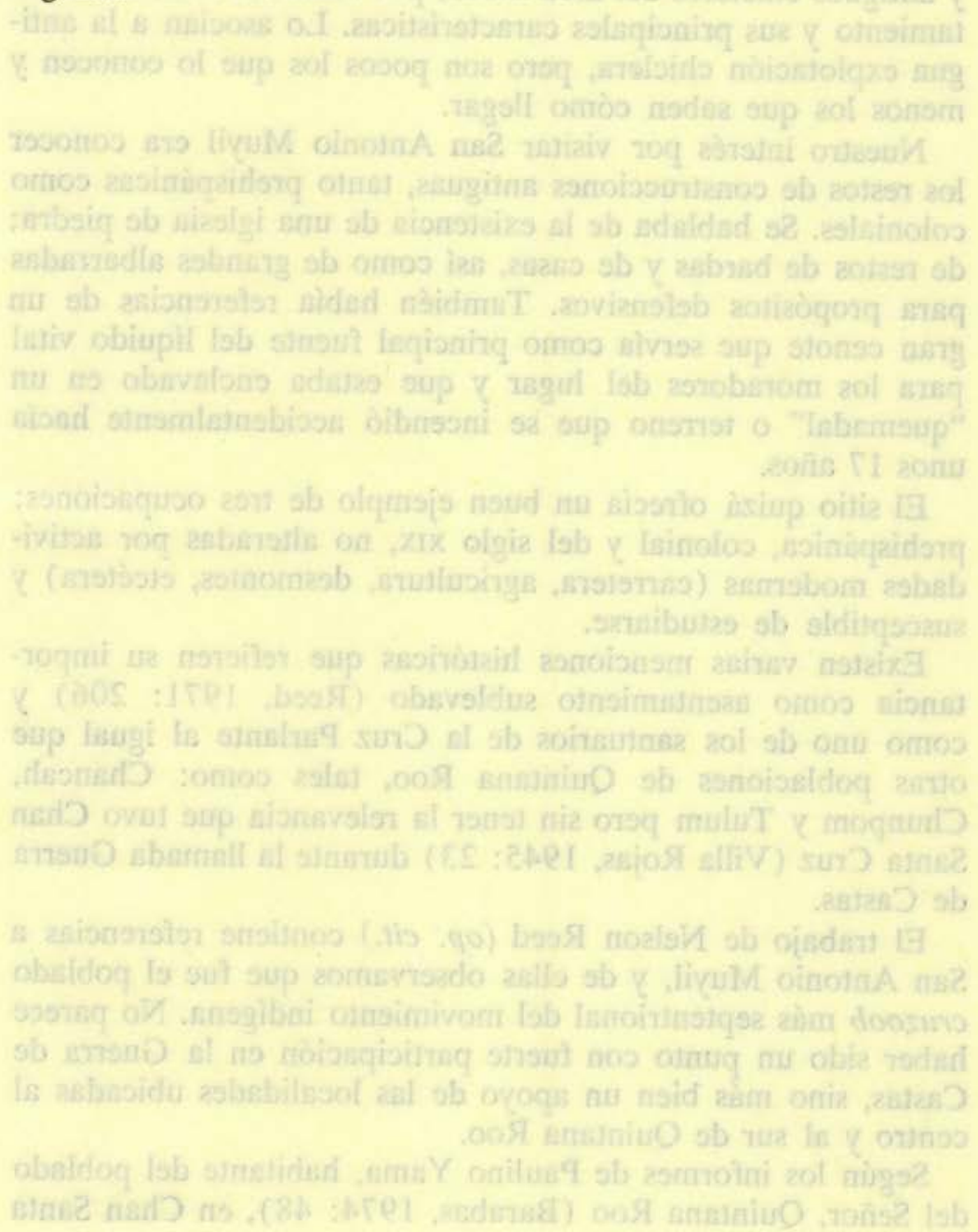




\section{APÉNDICE}

\section{Visita a San Antonio Muyil}

Diciembre de 1984

Esta localidad se encuentra en el norte de Quintana Roo, en medio de la selva mediana típica de la región. Los campesinos y antiguos chicleros del área saben, por tradición oral, del asentamiento y sus principales características. Lo asocian a la antigua explotación chiclera, pero son pocos los que lo conocen y menos los que saben cómo llegar.

Nuestro interés por visitar San Antonio Muyil era conocer los restos de construcciones antiguas, tanto prehispánicas como coloniales. Se hablaba de la existencia de una iglesia de piedra; de restos de bardas y de casas, así como de grandes albarradas para propósitos defensivos. También había referencias de un gran cenote que servía como principal fuente del líquido vital para los moradores del lugar y que estaba enclavado en un "quemadal" o terreno que se incendió accidentalmente hacía unos 17 años.

El sitio quizá ofrecía un buen ejemplo de tres ocupaciones: prehispánica, colonial y del siglo XIX, no alteradas por actividades modernas (carretera, agricultura, desmontes, etcétera) y susceptible de estudiarse.

Existen varias menciones históricas que refieren su importancia como asentamiento sublevado (Reed, 1971: 206) y como uno de los santuarios de la Cruz Parlante al igual que otras poblaciones de Quintana Roo, tales como: Chancah, Chunpom y Tulum pero sin tener la relevancia que tuvo Chan Santa Cruz (Villa Rojas, 1945: 23) durante la llamada Guerra de Castas.

El trabajo de Nelson Reed (op. cit.) contiene referencias a San Antonio Muyil, y de ellas observamos que fue el poblado cruzoob más septentrional del movimiento indígena. No parece haber sido un punto con fuerte participación en la Guerra de Castas, sino más bien un apoyo de las localidades ubicadas al centro y al sur de Quintana Roo.

Según los informes de Paulino Yama, habitante del poblado del Señor, Quintana Roo (Barabas, 1974: 48), en Chan Santa 
Cruz había un cedro divino en el que se talló por primera vez una cruz que comunicaba a los macehuales las estrategias a seguir. El árbol fue cortado por los soldados federales, pero, al no dominar la rebelión, los indígenas rindieron culto a los pedazos de madera y de ellos hicieron varias cruces. La mayor quedó en Chan Santa Cruz, que posteriormente pasó a Xcacal, y otras cruces menores se llevaron a los santuarios de San Antonio Muyil, Chunpom, Chancah y Tulum.

De la obra de Reed se infiere que San Antonio Muyil estuvo poblada en 1853 y que fue abandonada, posiblemente, poco después de 1900 (ibid.: 169, 234). Sin embargo, desconocemos si la localidad estuvo ocupada en la época prehispánica y si fue un asentamiento sucesivo hasta 1853. En un mapa de 1766 (Roys, et al., 1940: 4) el área donde se ubica la comunidad aparece como una zona despoblada.

A pesar de esto, Bartolomé y Barabas (1981: 47) dicen que de 1917 a 1929 se abrieron vías de comunicación para facilitar la explotación forestal en Quintana Roo, ubicando a San Antonio Muyil como la localidad más norteña para la extracción de chicle y madera. Posiblemente San Antonio Muyil funcionaba entonces como campamento chiclero, pero carecemos de la información suficiente para aseverarlo.

Por lo que se refiere al "colapso" de San Antonio Muyil, en contraposición a Reed (op. cit.), Bartolomé (1974: 9) señala que en 1950 el poblado "se eclipsó por causas no bien determinadas". A nuestro juicio no existen evidencias como mapas, textos, información de los habitantes más antiguos de la región o elementos en superficie que indiquen que San Antonio Muyil estuvo ocupada a mediados del presente siglo.

Por otra parte, recopilando los antecedentes de la región (Zapata, et al., 1980: 11-14), sabemos que entre los años de 1892 a 1895 en la península de Yucatán existían dos de los latifundios más extensos del país: la Hacienda Santa María y El Cuyo.

La primera quedaba comprendida en lo que hoy es el norte del estado de Quintana Roo. Ocupaba una superficie de 630, 679 ha. con una gran diversidad de productos agrícolas, pero especialmente bosques riquísimos en maderas preciosas y resinas comerciales. 
Para 1903 el Banco de Londres y México (BLM) centró sus mayores intereses en el territorio de Quintana Roo. Principalmente se dedicaba a obtener resina del chicozapote para su industrialización, así como a la extracción de maderas duras como el palo de rosa, palo de tinte, cedro y caoba. Éstas se exportaban, vía marítima, a Europa, primordialmente a Noruega. El embarque de los productos, rumbo al Viejo Mundo, se inició en Progreso, Yuc., pero alrededor de 1905 las buenas condiciones de calado de Puerto Morelos llevaron a construir un muelle, habilitándose como puerto principal. Al año siguiente comenzó la explotación industrial del coco, cuya exportación era dirigida a Inglaterra, donde se procesaba en aceite y dulces para luego enviarse de nuevo a Yucatán.

A principios del siglo xx (1911-1912) las centrales chicleras que se encontraban en los alrededores de Puerto Morelos se unificaron en una sola administración, con sede en las ruinas de Santa María, hoy Leona Vicario. El producto se exportaba básicamente a Estados Unidos. Pocos años después (alrededor de 1915), debido al fuerte movimiento económico que ocurría en la costa, las últimas familias (12 a 15) que quedaban en San Antonio Muyil abandonaron el poblado y se asentaron en Akumal (José González Avilés, comunicación personal, 1985).

El BLM, en 1924, cedió la concesión de las tierras a la familia Noriega, la cual laboró aproximadamente por espacio de cuatro años. A raíz de esto la administración del campo y los principales servicios (médicos y de comunicaciones) se trasladaron a Isla Mujeres y a Cozumel, lo que ocasionó que la población migrara poco a poco, y en Puerto Morelos sólo quedaron algunas familias. En ese mismo año se construyó la carretera Puerto Juárez-Puerto Morelos; cobró mayor auge la explotación del coco y la extracción del palo de tinte. Este último se enviaba a Europa en barcos noruegos rodeando a la península.

En 1928 el BLM tuvo que deslindar a la Hacienda Santa María, y para este fin se abrieron brechas. En los puntos claves de esta poligonal se levantaron grandes mojoneras de hasta $15 \mathrm{~m}$ de altura. Una de ellas se localizaba en el poblado de Tulum (4 km al sur de la zona arqueológica) y otra en San 
Antonio Muyil. La distancia aproximada entre estos dos puntos era de $36 \mathrm{~km}$.

En la década de 1930 don José González Avilés (comunicación personal, 1985) visitó San Antonio Muyil tres o cuatro veces con el fin de extraer palo de tinte y chicle. Señala haber observado los mismos elementos descritos por nosotros.

Por decreto presidencial, en 1935, se expropiaron las tierras del BLM y se repartieron en ejidos dedicados principalmente a la explotación del coco.

En cuanto a la ubicación de San Antonio Muyil, en los mapas presentados por Reed (ibid.: 169, 203), se indica que se halla en una región arbolada a unos $30 \mathrm{~km}$ al oriente de Cobá, o bien a $27 \mathrm{~km}$ aproximados al noroeste de Tulum. El mapa marca la existencia de un camino (seguramente de arria) entre Tulum y San Antonio Muyil. Otro plano (Pacheco Cruz, 1934: 8) señala la existencia de una vereda que parte de Pamul, pasa por San Antonio Muyil (marcándolo como un pueblo pequeño), Xcan, Chancenote, Tixcancal y Tizimín. Aquí el camino se divide hacia tres rumbos diferentes. Empero, los informantes nos señalaron que el sitio se hallaba a 20 ó $30 \mathrm{~km}$ al oriente de Tres Reyes. También supimos que a fines de 1984 se estaba abriendo una brecha que comunicaría en línea recta a San Antonio Muyil con la carretera Puerto Juárez-Carrillo Puerto, a fin de facilitar el acceso a un nuevo centro de población ejidal que cambiaría al nombre de Cecilio Chí, como homenaje al caudillo maya, uno de los principales dirigentes del movimiento indígena de 1847.

En principio, pensamos caminar desde Tres Reyes, pero por carecer de guía, al enterarnos de que la brecha ya estaba terminada y de que representaba un acceso más corto $(15 \mathrm{~km})$, optamos por llegar al sitio desde el oriente.

En el kilómetro 56.200 de la carretera Puerto Juárez-Carrillo Puerto, a poca distancia al norte del límite del Rancho San Miguel Arcángel, iniciamos la caminata (domingo 9 de diciembre) rumbo al poniente. Desafortunadamente a los cuatro kilómetros la brecha que seguíamos concluyó y fue necesario buscar el "picado" por donde habían pasado los brecheros procedentes de San Antonio Muyil. En esta labor fue valiosísima la ayuda del Jefe de Custodios de Cobá, Leonardo Falcón Kinil, quien 
gracias a su experiencia en el "monte" nos condujo hasta nuestro objetivo.

El primer día pasamos por el campamento chiclero Granito de Oro, hoy abandonado. La vegetación tenía una altura promedio de $25 \mathrm{~m}$ y el terreno básicamente era de ek luum (tierra negra), hojarasca y frecuentes raíces a flor de tierra. Durante el recorrido vimos una piara de pecaríes, venados, varios pavos de monte, chachalacas, diversas aves, un grupo de monos y una depresión en el terreno que por efectos de la penumbra del atardecer parecía un cenote. Poco después acampamos al oscurecer y sentimos la comezón propia del "pinolillo" o garrapata rojiza muy pequeña. En esa primera jornada caminamos alrededor de 20 kilómetros.

El segundo día (lunes 10 de diciembre) continuamos la caminata hacia el poniente. Pasamos cerca de otro campamento chiclero abandonado que estaba a unos cuatro kilómetros del punto donde pernoctamos. A los seis kilómetros del antiguo punto chiclero advertimos un cambio en la vegetación, pasando de ser monte alto a un área con flora secundaria, propia de quemadal. También, casi simultáneamente, la brecha de acceso al sitio surgió de nuevo. Aproximadamente a los cuatro kilómetros llegamos al pie de una gran ceiba y cerca de ella vimos el ancho y profundo cenote de San Antonio Muyil.

En la localidad había ocho campesinos que recientemente habían empezado a desmontar algunos pequeños sectores y a construir dos casas de materiales perecederos. Platicamos con ellos y señalaron desconocer la existencia de una iglesia antigua o de grandes albarradas defensivas. Después hicimos un breve recorrido en el cual observamos una gran abundancia de albarradas bajas que delimitaban espacios cuadrangulares. Dentro de tales solares había vestigios de casas habitación de cimientos elipsoidales y circulares, así como posibles restos de gallineros. Entre las ruinas se observaron fragmentos de botellas de vidrio de fondo convexo, todas ellas manufacturadas mediante la técnica de soplado y de color verde oscuro; la longitud promedio de estos envases era de $28 \mathrm{~cm}$. También se localizaron algunos metates de piedra caliza, ápodos, con dimensiones promedio de $36 \mathrm{~cm}$ de largo por $27 \mathrm{~cm}$ de ancho, con $4 \mathrm{~cm}$ de grosor en una cabecera y $9 \mathrm{~cm}$ de espesor en la otra. 
Algunas albarradas estaban separadas por pasajes angostos, a manera de calles, y una de estas posibles calzadas, más ancha que las demás por tener una amplitud de $12 \mathrm{~m}$ en vez de 3 a $4 \mathrm{~m}$, conduce directamente al cenote formando una pequeña explanada al borde de éste.

Esta importante fuente de agua tiene un diámetro aproximado de $20 \mathrm{~m}$ y una altura de $9 \mathrm{~m}$ desde la superficie hasta el espejo del agua. Las paredes son verticales en algunos sectores y cóncavas en otros, de modo que es difícil descender, a pesar de haber numerosas raíces de copó, ramón, pich y de otras especies arbóreas de gran tamaño que llegaban hasta el agua y penetraban en ella. El manto acuífero era cristalino y tenía una profundidad promedio de $5 \mathrm{~m}$ y se observaron algunos bagres hasta de $20 \mathrm{~cm}$ de longitud. El perímetro del cenote está rodeado por una albarrada de grandes bloques; algunos conservan su forma rectangular. Posiblemente este parapeto fue elaborado durante la ocupación colonial (?). Es dudoso que para la época de la cual hay mayores evidencias de actividad (siglo xIx), los habitantes se ocuparon de bardear el cenote en lugar de dedicar la mayoría de sus esfuerzos a sostener las batallas de una guerra que ya estaban perdiendo.

A unos 50 metros de la ceiba se encuentra un amontonamiento de piedras que semeja una mojonera de dos metros de altura máxima. Ésta se halla sobre una nivelación artificial del terreno.

Al finalizar el breve recorrido por el sitio entrevistamos de nuevo a los campesinos del lugar, a fin de saber si existía un camino más corto de San Antonio Muyil a la costa. Así supimos que había una antigua brecha chiclera de $9 \mathrm{~km}$ hacia el sureste que llegaba hasta las instalaciones de un pozo de agua potable (hoy abandonado) a partir del cual se inicia un camino de terracería que corre $8 \mathrm{~km}$, también hacia el sureste, y llega a la carretera Puerto Juárez-Carrillo Puerto, justo enfrente de la entrada a Akumal.

El martes 11 de diciembre, al amanecer, emprendimos el regreso siguiendo el camino antes mencionado. En esta ocasión fueron más abundantes los parajes con afloramientos rocosos. También cabe anotar que a lo largo de gran parte de los 8 $\mathrm{km}$ de terracería se halla abandonada la tubería que condujera 
el agua potable. Hoy día existe un nuevo pozo a sólo un kilómetro de la carretera.

En las pláticas con los campesinos y durante el retorno a la costa, nos comentaron de la existencia de una especie de primate al que denominan "acatucha". Según las descripciones, se trata de un mono grande parecido al gibón. Tiene la altura de un hombre de baja estatura, es bípedo, y su principal característica es subir al anochecer a los árboles donde duermen los monos araña y atacarlos rompiéndoles el cráneo para devorar la masa cefálica.

En noviembre de este año mataron a uno de estos seres, que al parecer se están extinguiendo rápidamente, en una milpa que se encuentra entre Tres Reyes y San Antonio Muyil.

Tradicionalmente en las comunidades rurales se amenaza a los niños de mala conducta con la probable llegada del "acatucha". Como posible derivación de esta conseja popular, en el medio urbano se habla del "tucho", como agresor infantil. Dos expresiones comunes en Yucátan son: "Pintas al tucho y luego le tienes miedo" y "Te va a llevar el tucho", aparentemente equivalentes al "coco" o personaje molévolo de otras partes del país.

Es posible que el término "acatucha" proceda de $a k a b$ (noche) y "tucha" (mono).

Para finalizar, calculando las horas/caminata nos dio la impresión de haber recorrido unos cuatro kilómetros más de los diecisiete que se dice existen entre Akumal y San Antonio Muyil.

En estas últimas líneas queremos hacer patente nuestra admiración, amistad y agradecimiento a Leonardo Falcón Kinil, quien, $\sin$ instrumento alguno, y careciendo de brechas o veredas, nos guió a lo largo de muchos kilómetros a través de la densa selva quintanarroense. 


\section{BIBLIOGRAFIA}

Álvarez, Ticul y Francisco de Lachica

1974 "Zoogeografía de los vertebrados de México", en El Escenario Geográfico: 219-302 INAH-SEP, México.

ANDRews IV, E. Wyllys y ANthony P. ANDrews

1975 A preliminary study of the ruins of Xcaret, Quintana Roo, Mexico. Middle American Research Institute; Pub. 40, Tulane University, New Orleans.

Barabas, Alicia M.

1974 "Profetismo, milenarismo y mesianismo en las insurrecciones mayas de Yucatán", en Cuadernos de los Centros Regionales: No. 5: 29-58, Dirección de Centros Regionales, INAH, México.

Barrera M., Alfredo; Alfredo Barrera V. y Rosa María LÓPEZ F.

1976 Nomenclatura etnobotánica maya, Colección Científica No. 36, INAH, México.

Bartolomé, Miguel Alberto

1974 "La iglesia maya de Quintana Roo", en Cuadernos de los Centros Regionales: No. 5: 1-28, Dirección de Centros Regionales, INAH, México.

\section{Y Alicia Mabel Barabas}

1981 La resistencia maya, Colección Científica No. 53, INAH, México.

Benavides C., Antonio y Antonio P. Andrews

1979 Ecab: poblado y provincia del siglo XVI en Yucatán, Cuadernos de los Centros Regionales, INAH, México.

1981a Los caminos de Cobá y sus implicaciones sociales, INAH, México.

1981b Cobá. Una ciudad prehispánica de Quintana Roo, Guía Oficial, INAH, México.

Comisión de Estudios del Territorio Nacional (CETENAL) y Universidad Nacional Autónoma de México

1970 Carta de Climas: Cozumel, 16Q IV, Escala 1: 50,000, Talleres Gráficos de la Nación, México. 
CORTÉs, HERNÁN

1973 Cartas de Relación, Colección "Sepan Cuantos..." No. 7, Ed. Porrúa, México.

Charnay, Desiré

1978 Viaje a Yucatán a fines de 1886, Cuadernos Cuatro, Fondo Editorial de Yucatán, México.

DIAZ, JUAN

1958 Itinerario de Juan de Grijalva 1518 (Cr. R. Menéndez; Ed.), Mérida.

Díaz del Castillo, Bernal

1970 Historia verdadera de la Conquista de la Nueva España, Ed. Porrúa; 8a. edición, México.

Escalona Ramos, Alberto

1946 "Algunas ruinas prehistóricas en Quintana Roo", en Boletín de la Sociedad Mexicana de Geografía y Estadistica, Tomo LXI, No. 3: 513-628, México.

Freidel, David A. Y Jeremy A. Sabloff

1984 Cozumel. Late Maya settlement patterns, Academic Press, New York.

Folan, William J., Ellen R. Kintz y Larraine A. Fletcher

1983 Cobá. A classic Maya metropolis, Academic Press, New York.

González de la M., Rocío y Elia Trejo A.

1981 "Playa del Carmen: excavaciones en la costa oriental de Quintana Roo. Temporada 1978", en Memoria del Congreso Interno 1979: 123-138, Centro Regional del Sureste, INAH, México.

LOTHROP, SAMUEL K.

1924 Tulum: an archaeological study of the east coast of Yucatan, Carnegie Institution of Washington; Pub. 335, Washington.

Mendieta, Rosa María y Silvia del Amo

1981 Plantas medicinales del Estado de Yucatán, INIREB, Xalapa, Ver.

Miller, Arthur G.

1977 "The Maya and the sea: trade and cult at Tancah and Tulum, Quintana Roo, Mexico", en The Sea in the Pre-Columbian World: 96-138, Elizabeth P. Benson 
(Ed.) Dumbarton Oaks Research Library \& Collections, Trustees for Harvard University, Washington.

\section{Pacheco Cruz, Santiago}

1934 Estudio etnográfico de los mayas del ex-territorio Quintana Roo, Imprenta Oriente, Mérida.

ReEd, NeLson

1971 La guerra de castas de Yucatán, Editorial Era, México.

Robles C., Fernando

1976 "Ixil centro agrícola de Cobá", en Boletín de la ECAUDY No. 20: 13-43, Mérida.

1980 Museo Arqueológico de Xelhá, Centro Regional del Sureste, INAH, México.

Roys, Ralph L., France V. Scholes and Eleanor B. Adams

1940 "Report and census of the indians of Cozumel, 1570", en Contributions to American Anthropology and History, Vol. VI Nos. 30-34, Pub. 523, Carnegie Institution of Washington, Washington.

Sabloff, Jeremy A., y William L. Rathje (Eds.)

1975 A study of changing precolumbian commercial systems, Monographs of the Peabody Museum, No. 3, Harvard University, Cambridge, Mass.

SANDERS, William T.

1960 Prehistoric ceramics and settlement patterns in Quintana Roo, Mexico, Carnegie Institution of Washington; Pub. 606, Contrib. 60, Washington.

Secretaría de la Defensa Nacional

1972 Carta Estados Unidos Mexicanos; Kantunilkin, Escala 1: 100 000, Mapoteca del CRY-INAH, Mérida.

Thompson, J. Eric; Harry E. D. Pollock y Jean Chariot

1932 A preliminary study of the ruins of Coba, Quintana Roo, Mexico, Carnegie Institution of Washington; Pub. 424, Washington.

1945 "A survey of the northern Maya area", en American Antiquity; Vol. XI, No. 1: 2-24 The Society for American Archaeology, Manasha, Wisconsin.

Vargas Pacheco, ERnesto

1978 "Los asentamientos prehispánicos y la arquitectura en 
la Isla Cancún, Quintana Roo", en Estudios de Cultura Maya; Vol. XI: 95-112, UNAM, México.

Villa RoJas, AlFonso

1945 The Maya of east central Quintana Roo, Carnegie Institution of Washington; Pub. 559, Washington.

Wing, Elizabeth S.

1978 "Use of dogs for food: an adaptation to the coastal environment", en Prehistoric Coastal Adaptations: 2941, Stark y Voorhies (Eds.), Academic Press, New York.

Zapáta P., Renée LoRelei; Bertha Rosa Toraya T., y Miriam Cuevas G.

1980 Trabajo de campo realizado en la comunidad de Puerto Morelos, Quintana Roo, Mecanuscrito inédito, Mérida. 